
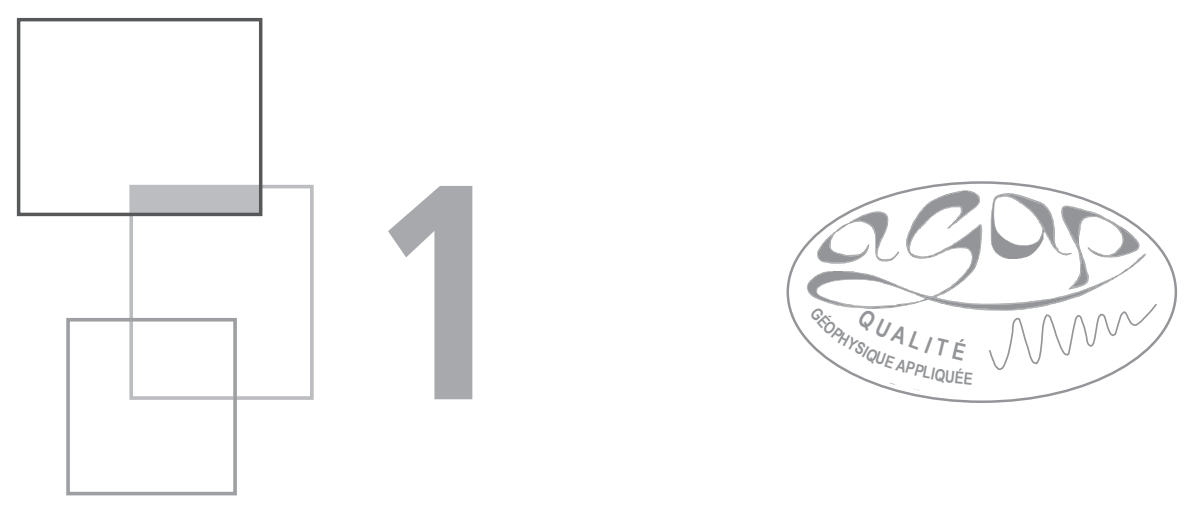

\title{
Shear velocity measurement in boreholes
}

\author{
C. Vergniault, J.-L. Mari
}

\subsection{Context}

\subsubsection{Overview of invasive and non-invasive $V_{s}$ measurements}

Measurement of shear waves $(S)$ can be invasive (borehole seismic surveys and logging) or non-invasive (surface waves (Multi analysis of surface waves: MASW) and ambient noise (Ambiance measurement vibration: AMV)). Obviously, each method has advantages and disadvantages that the project manager (client or subcontractor) must evaluate to select the most suitable method for the project. To assist in this process, Table 1.1 summarizes the pros and cons of each method.

This chapter of Well seismic surveying and acoustic logging is published under Open Source Creative Commons License CC-BY-NC-ND allowing non-commercial use, distribution, reproduction of the text, via any medium, provided the source is cited.

(C) EDP Sciences, 2018

DOI: $10.1051 / 978-2-7598-2263-8 . c 003$ 
Table 1.1 Pros and cons of invasive and non-invasive methods.

\begin{tabular}{|c|c|c|c|c|c|}
\hline & Method & Target depth & $\begin{array}{l}\text { Vertical } \\
\text { resolution }\end{array}$ & Limitations & $\begin{array}{c}\text { Offshore } \\
\text { application }\end{array}$ \\
\hline \multirow{3}{*}{ 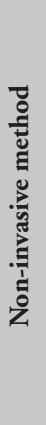 } & $S$ refraction & $\begin{array}{l}50 \mathrm{~m} \text {, but } \\
\text { sometimes less } \\
\text { than } 10 \mathrm{~m} \text { in } \\
\text { an industrial } \\
\text { environment }\end{array}$ & Several meters & $\begin{array}{l}\text { Affected by noise } \\
\text { in an industrial } \\
\text { environment, } \\
\text { limited by velocity } \\
\text { reversals }\end{array}$ & Yes \\
\hline & MASW & 15 to $20 \mathrm{~m}$ & Several meters & $\begin{array}{l}\text { Need for a tabular } \\
\text { medium in the } \\
\text { investigated area }\end{array}$ & Yes \\
\hline & AMV & $\begin{array}{l}\text { Several hundred } \\
\text { meters }\end{array}$ & $\begin{array}{l}\text { Several meters } \\
\text { to decameters }\end{array}$ & $\begin{array}{l}\text { Need for a tabular } \\
\text { medium in the } \\
\text { investigated area }\end{array}$ & Not currently \\
\hline \multirow{2}{*}{ 占 } & $\begin{array}{l}\text { Monopole sonic } \\
\text { logging }\end{array}$ & $\begin{array}{l}>1,000 \mathrm{~m}, \text { for } \\
\text { deep boreholes, } \\
\text { of prospective } \\
\text { exploration }\end{array}$ & $\begin{array}{l}\text { Several } \\
\text { decameters }\end{array}$ & $\begin{array}{l}\text { Requires an } \\
\text { uncased borehole } \\
\text { and for } V_{s} \text { to be } \\
\text { greater than } V_{p} \text { in } \\
\text { the borehole fluid }\end{array}$ & Yes \\
\hline & $\begin{array}{l}\text { PSSL or dipole } \\
\text { sonic logging }\end{array}$ & $\begin{array}{l}\text { Up to } 300 \mathrm{~m} \text { for } \\
\text { geotechnical deep } \\
\text { boreholes }\end{array}$ & $1 \mathrm{~m}$ & $\begin{array}{l}\text { Preferably in an } \\
\text { uncased borehole } \\
\text { but it's also possible } \\
\text { to use PSSL } \\
\text { through a sealed } \\
\text { case }\end{array}$ & $\begin{array}{l}\text { Yes, but with } \\
\text { uncased holes }\end{array}$ \\
\hline \multirow{3}{*}{ 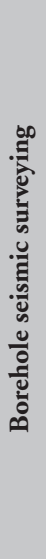 } & Crosshole & $\begin{array}{l}\text { Up to } 50 \mathrm{~m} \text {, } \\
\text { exceptionally } 100 \mathrm{~m}\end{array}$ & $1 \mathrm{~m}$ & $\begin{array}{l}\text { Requires } 2 \\
\text { boreholes, either } \\
\text { uncased or with } \\
\text { sealed casings and } \\
\text { limited deviation }\end{array}$ & $\begin{array}{l}\text { Generally too } \\
\text { expensive }\end{array}$ \\
\hline & Downhole & $\begin{array}{l}\text { Up to } 50 \mathrm{~m} \text {, } \\
\text { exceptionally } \\
100 \mathrm{~m} \text {, for S-waves. } \\
\text { Can also be very } \\
\text { deep for P-waves } \\
(>1,000 \mathrm{~m})\end{array}$ & Several meters & $\begin{array}{l}\text { Requires } 1 \\
\text { borehole, uncased } \\
\text { or sealed cased }\end{array}$ & $\begin{array}{l}\text { Yes for P-waves. } \\
\text { Remains too } \\
\text { complicated for } \\
\text { S-waves }\end{array}$ \\
\hline & Uphole & $\begin{array}{l}10 \mathrm{~m} \text { for } \mathrm{S} \text {-waves, } \\
50 \mathrm{~m} \text { for } \mathrm{P} \text {-waves }\end{array}$ & Several meters & $\begin{array}{l}\text { Difficult to have a } \\
\text { powerful S source } \\
\text { without damaging } \\
\text { the casing }\end{array}$ & $\begin{array}{l}\text { Difficult to have } \\
\text { an adapted } S \\
\text { source }\end{array}$ \\
\hline
\end{tabular}

Based on the capabilities and limitations of each method, described in Table 1.1, several choices are possible depending on the project's objective and the level of knowledge about the site. These choices are summarized in Table 1.2. Finally, the economic aspect is also a key factor in choosing between the possible options. 
Table 1.2 Method suitability according to objective.

\begin{tabular}{|l|l|l|l|l|}
\hline Requirement & \multicolumn{2}{|l|}{$\begin{array}{l}\text { Modeling the ground response for the } \\
\text { purposes of sensitive construction design }\end{array}$} & $\begin{array}{l}\text { Designing a construction to conform to } \\
\text { the Eurocode 8 soil classification }\end{array}$ \\
\hline $\begin{array}{l}\text { Level of } \\
\text { knowledge } \\
\text { about the site }\end{array}$ & $\begin{array}{l}\text { Overall knowledge } \\
\text { of the site is } \\
\text { insufficient to } \\
\text { establish velocity } \\
\text { logging of the } \\
\text { ground under the } \\
\text { proposed building }\end{array}$ & $\begin{array}{l}\text { Detailed knowledge } \\
\text { (velocity logging) } \\
\text { available at several } \\
\text { points around the } \\
\text { site, but not in the } \\
\text { ground below the } \\
\text { proposed building }\end{array}$ & $\begin{array}{l}\text { No special } \\
\text { knowledge }\end{array}$ & $\begin{array}{l}\text { The } \mathrm{V}_{\mathrm{s}} 30 \text { is known } \\
\text { in several points } \\
\text { around the site, but } \\
\text { not for the ground } \\
\text { below the proposed } \\
\text { building }\end{array}$ \\
\hline $\begin{array}{l}\text { Recommended } \\
\text { measurement }\end{array}$ & $\begin{array}{l}\text { Crosshole coupled } \\
\text { with downhole or } \\
\text { PSSL coupled with } \\
\text { crosshole in the top } \\
10 \text { meters }\end{array}$ & $\begin{array}{l}\text { Downhole or } \\
\text { PSSL coupled with } \\
\text { MASW and AMV }\end{array}$ & $\begin{array}{l}\text { Downhole coupled } \\
\text { with MASW and } \\
\text { AMV }\end{array}$ & $\begin{array}{l}\text { MASW and AMV } \\
\text { if space is sufficient } \\
\text { and unaffected } \\
\text { by multiple } \\
\text { underground } \\
\text { networks }\end{array}$ \\
\hline
\end{tabular}

This chapter addresses invasive geophysical methods to obtain a $V_{s} \log$, i.e. the following methods: downhole, uphole, crosshole and logging. The case studies presented are from EDF feedback from numerous soil surveys conducted over the last 5 years, as well as from the Inter Pacific research project whose objective was to compare geophysical methods for site seismic characterization (Garofalo, 2016). Non-invasive methods are not covered in this document.

\subsubsection{Applications}

The most common application concerns the design and sizing of civil engineering structures. Indeed, in the Eurocode 8 soil classification, one of the three main parameters for classifying soils is based on a average of shear wave propagation velocity within the top 30 meters. This parameter is conventionally called " $\mathrm{V}_{s} 30$ ".

Table 1.3 Mechanical parameters according to $V_{p}, V_{s}$ and $\rho$ (from Bourbié, 1986).

\begin{tabular}{|l|c|}
\hline Mechanical parameter & Equation with $\mathbf{V}_{\mathbf{p}}, \mathbf{V}_{\mathbf{s}}$ and $\rho$ \\
\hline Young's modulus, $\mathbf{E}_{\mathbf{d m a x}}(\mathrm{Pa}):$ & $\rho \mathrm{V}_{\mathrm{S}}^{2} \frac{3 \mathrm{~V}_{\mathrm{P}}^{2}-4 \mathrm{~V}_{S}^{2}}{\mathrm{~V}_{\mathrm{P}}^{2}-\mathrm{V}_{S}^{2}}$ \\
\hline Lamé constant, $\boldsymbol{\lambda}(\mathrm{Pa})$ & $\rho\left(\mathrm{V}_{\mathrm{P}}^{2}-2 \mathrm{~V}_{\mathrm{S}}^{2}\right)$ \\
\hline Bulk modulus, $\mathbf{K}(\mathrm{Pa})$ & $\rho\left(\mathrm{V}_{\mathrm{P}}^{2}-\frac{4}{3} \mathrm{~V}_{\mathrm{S}}^{2}\right)$ \\
\hline The shear modulus, rigidity or Coulomb's coefficient $\left(\mathbf{G}_{\mathrm{dmax}}\right.$ or $\boldsymbol{\mu}$ in $\left.\mathrm{Pa}\right)$ & $\rho \mathrm{V}_{\mathrm{S}}^{2}$ \\
\hline Poisson's ratio, $\boldsymbol{\gamma}$ (without dimension) & $\frac{\mathrm{V}_{\mathrm{P}}^{2}-2 \mathrm{~V}_{\mathrm{S}}^{2}}{2\left(\mathrm{~V}_{\mathrm{P}}^{2}-\mathrm{V}_{\mathrm{S}}^{2}\right)}$ \\
\hline
\end{tabular}


Moreover, for a given density, the P and S measurements in boreholes also enable the determination of in-situ parameters necessary to define a model that remains elastic under small deformations (Table 1.3). There are essentially two moduli: the Young's modulus and the shear modulus.

\subsubsection{Environmental conditions}

It is important to note that, in the geotechnics field, drilling for invasive measurements generally crosses unstable terrain. Hence, they are often lined with a casing or PVC tubing that is sealed to the formation with cement grout.

Seal quality is paramount to enable a good transmission of seismic signals. Therefore, drilling and sealing must meet the standards described in ASTM D7400 for downhole and D4428 for crosshole.

The key points of this phase can be summarized in Table 1.4.

Table 1.4 Summary of hole parameters according to ASTM standards for geophysical borehole measurements.

\begin{tabular}{|l|l|}
\hline Max drilling diameter & $175 \mathrm{~mm}$ (7 in) \\
\hline Internal casing diameter & 50 to $100 \mathrm{~mm}$ (2 to 4 in) \\
\hline Tubing type & PVC or aluminum, closed at the base \\
\hline Sealing grout & $\begin{array}{l}\text { Bentonite-cement grout with a density close to that of the surrounding } \\
\text { soil to limit the energy loss by this waveguide }\end{array}$ \\
\hline
\end{tabular}

For PVC-cased boreholes, it is possible to carry out a cementation control through a Cement Bond Log and Variable Density Log (CBL-VDL), even though this tool was initially developed for steel casings (see Chapter 3). The CBL-VDL log is a recording carried out with an acoustic tool centered in the borehole, with a piezoelectric source and receiver that are distinct with a distance between them of $3 \mathrm{ft}$ and $5 \mathrm{ft}$ for CBL and VDL respectively. If the coupling is good (low acoustic velocity contrast) most of the energy is transmitted and the energy of the refracted waves is low, which visually translates into low CBL and VDL amplitudes (gray rectangles in Figure 1.1). If this is not the case, the amplitude of the recorded waves is high. This signal is somewhat "rectilinear" in nature (red rectangle in Figure 1.1). It should be noted that if the formation has a high velocity compared to that of the casing $(2,100$ to $2,200 \mathrm{~m} / \mathrm{s}$ for PVC compared to $5,600 \mathrm{~m} / \mathrm{s}$ for steel), then the refracted waves in the formation will arrive first, thus masking the refracted waves in the casing (orange rectangle in Figure 1.1). On the other hand, if these waves dominate, it means that the entirety of the casing, grout and formation is adherent. 

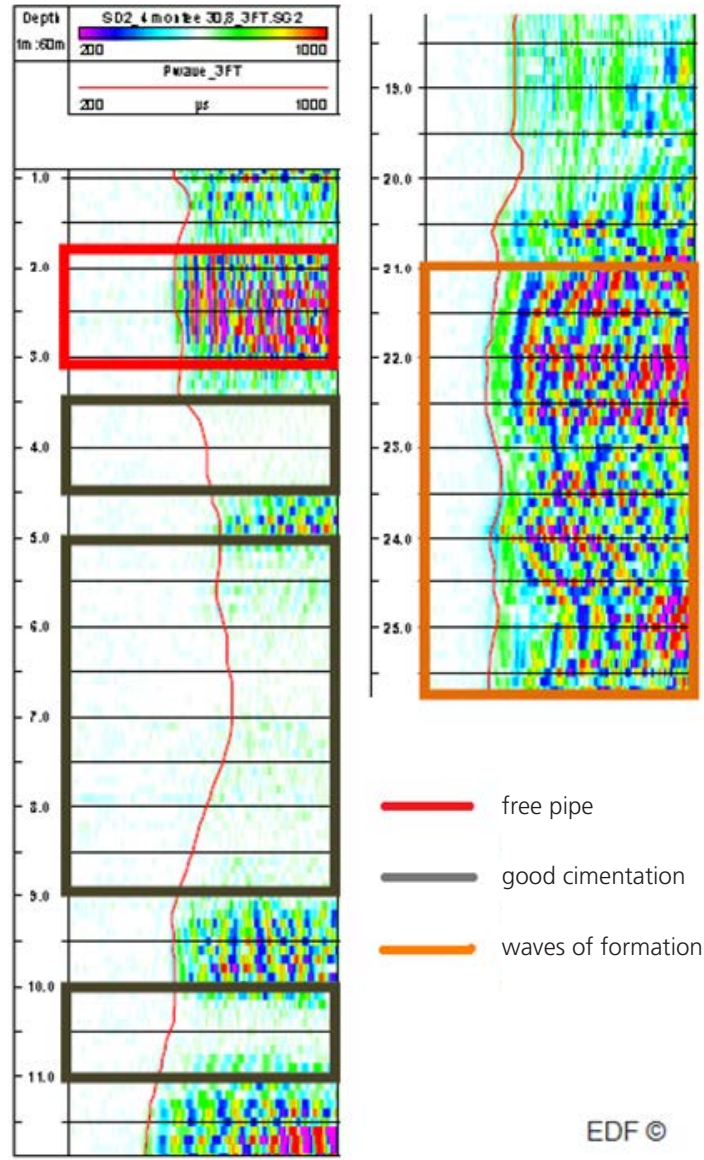

EDF $\odot$

Figure 1.1 Illustration of a Full wave sonic log used as a CBL-VDL to evaluate the quality of the cementation (LIM Logging acquisition for EDF).

This logging can be carried out with an acoustic tool of the sonic full waveform type. This is a necessity for a crosshole through an unstable formation (sandygravelly). Indeed, depending on the results, the allocation of emitting and receiving boreholes may be reviewed.

\section{$1.2 \quad \mathbf{V}_{\mathrm{s}}$ measurements by borehole seismic method}

Borehole transmission seismic surveying can be illustrated as a special type of Vertical Seismic Profiling (VSP, see Chapter 2) where the focus of interest is not the waves reflected at the interfaces, but the time of first arrival of the transmitted wave 
between the source at the surface and the receiver in the borehole. This is illustrated in Figure 1.2 below.
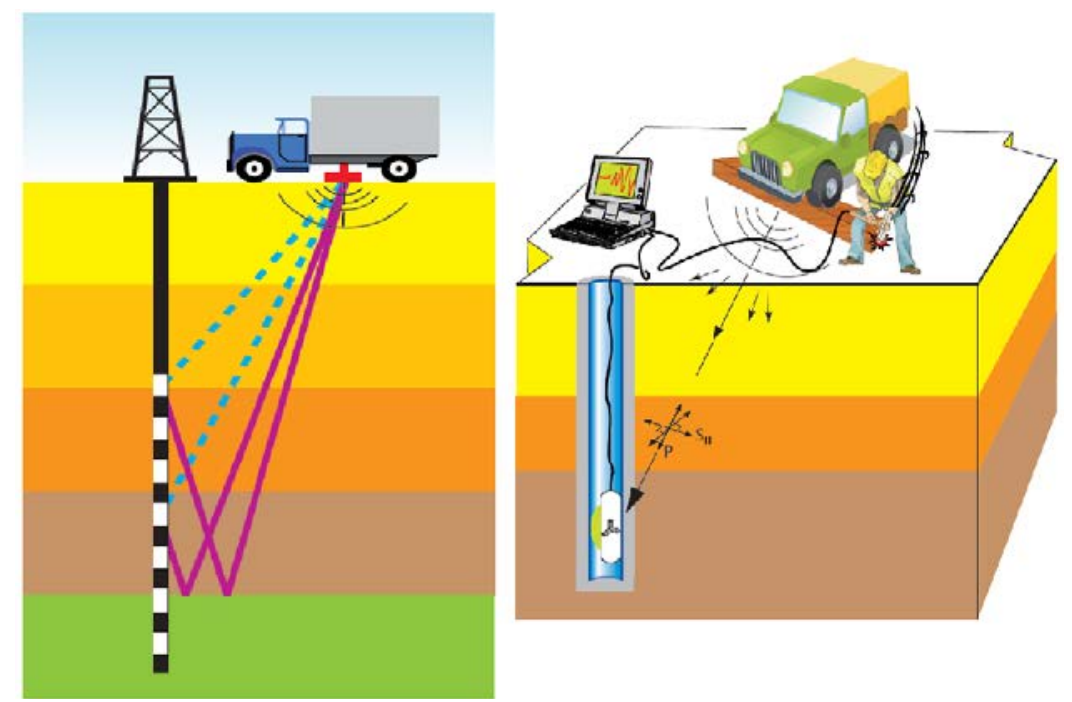

Figure 1.2 Illustration of the seismic raypath during a VSP or check shot (left) and a downhole (right). Reflected waves shown in purple; direct waves shown as dotted lines.

Regarding the study of transmitted or direct waves, in petroleum seismic prospecting, we refer more to check shots and also to seismic coring.

- In general, a check shot is carried out on the whole depth of an oil borehole (kilometric scale). It is used for seismic calibration, i.e. the geological characterization of seismic markers. Indeed, check shot results are presented in the form of graphs: time-depth, mean velocities of intervals, mean quadratic velocities as a function of the depth and the geological formations encountered in the borehole.

- Seismic coring is usually carried out in a shallow borehole (hectometric or decametric scale). It is used to determine the weathering zone (WZ) parameters, particularly its thickness and velocity, which are essential parameters for static corrections. Often its acquisition follows an uphole configuration (source in borehole, such as dynamite) rather than downhole (source on surface).

Geotechnics tends to focus on downhole $(\mathrm{DH})$, and also on shear waves $(\mathrm{S})$ in particular. For applications requiring a detailed evaluation of the $\mathrm{V}_{\mathrm{s}}$ logging as a function of depth (modeling ground response for construction design purposes), we often favor the measurement of transmission between boreholes, enabling the establishment of a velocity profile with a metric step, referred to as crosshole. 


\subsubsection{Downhole}

During a downhole acquisition, the seismic receiver is inside the borehole and the source is on the surface. Alternative configurations can be implemented with a seismic receiver in a cone penetrometer (Seismic Cone Penetration Testing - SCPT) or in a dilatometer (SDMT). In addition, a configuration with two receivers separated by a fixed distance is also possible. Depending on the type of strike on the ground surface (vertical or horizontal), the seismic source can generate a signal containing a maximum of energy in the compression wave $(\mathrm{P})$ or the shear wave $(\mathrm{S})$, see Figure 1.3.

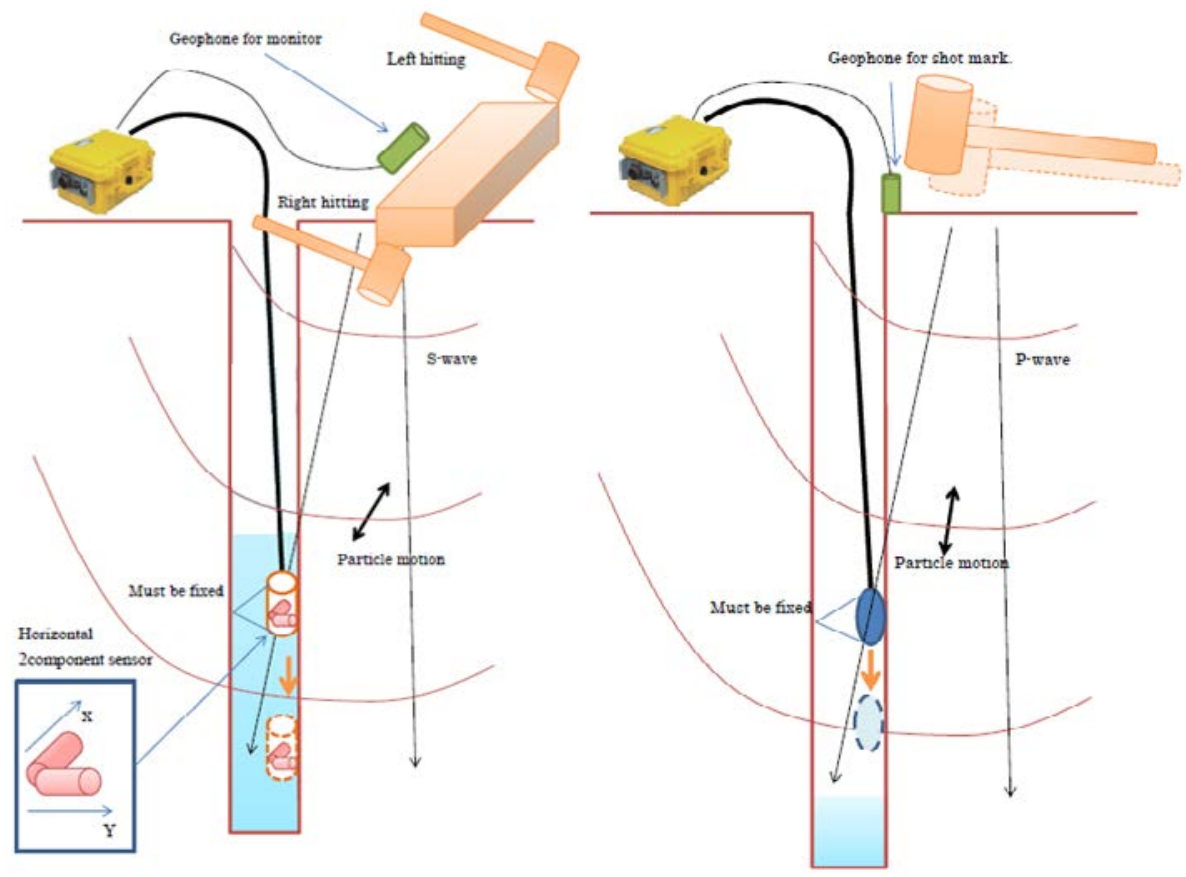

Figure 1.3 Typical configuration of a downhole where the shear waves are mainly recorded by horizontal components and the compression wave by the vertical component of the geophone in the borehole (according to Seis/mager technical documents, 2013).

\subsubsection{The acquisition device}

It is necessary to dissociate the acquisition and analysis of compression waves (P) and shear waves $(S)$. 


\subsection{Sources}

The standard ASTM D7400-08 (Standard Test Methods for Downhole Seismic Testing) clearly defines the most common $S$ source. It utilizes a beam of $2.4 \mathrm{~m}$ long and $15 \mathrm{~cm}$ thick, on which a vehicle can be positioned to ensure good coupling. An $S_{H}$ wave-rich signal is then obtained by lateral strikes on the sides of the beam, with a hammer of 5 to $15 \mathrm{~kg}$. The hammer can be mounted onto a pivoting axis as shown in the photos in Figure 1.4.
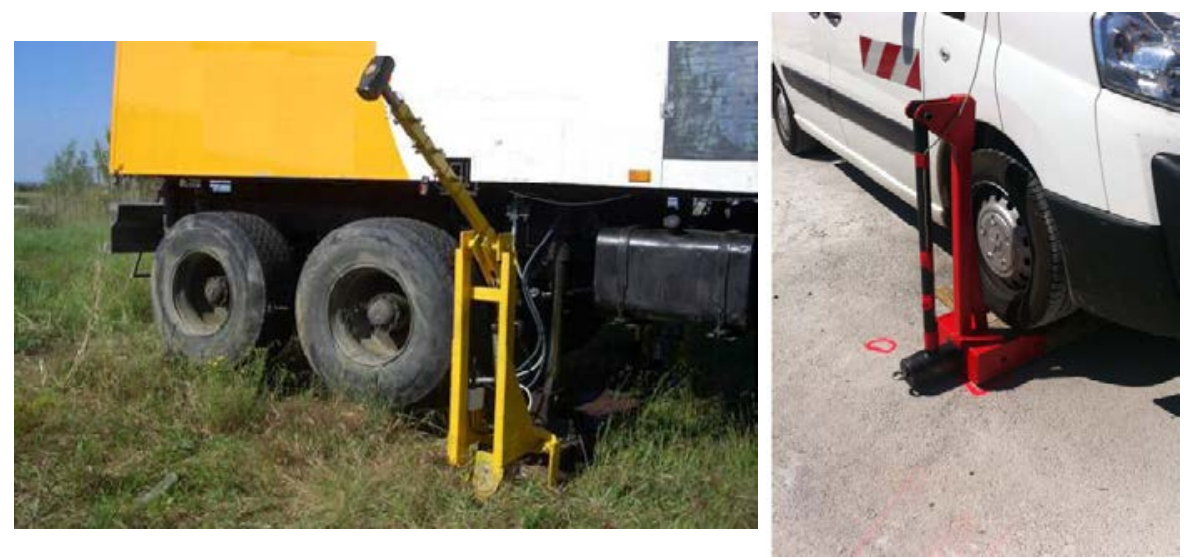

Figure 1.4 Illustration of an S source used in downhole testing which complies with the ASTM standard (IgeoTest source on the left, IMG source on the right).

To generate $P$ waves, an anvil can be vertically struck, either next to the beam on the axis between the midpoint and the borehole head, or next to each end of the beam.

\section{Choice of source location}

The distance between the midpoint of the beam and the probe (offset) must be carefully selected to limit the impact of tube waves, refracted waves and the angle of incidence. This distance is generally between 1 and $3 \mathrm{~m}$. If a larger offset is required ( 4 to $6 \mathrm{~m}$ ) or if the medium has several different velocity layers in the first 10 meters, then the refracted waves and actual paths (Snell-Descartes law) must be taken into account in the analysis (see Figure 1.5).

The impact of tube waves is a reality that must be taken into account. Figure 1.6 shows downhole data from a borehole full of water (blue signal), and then without water (black signal). This shows the complexity of the tube wave signal: a time of $60 \mathrm{~ms}$ at $30 \mathrm{~m}$ is not consistent with a simple signal reflected at the bottom and transiting through the water. The velocity corresponds more to that of a guided mode transiting at the water-casing interface (see Chapter 2, paragraphs on acoustic waves). 

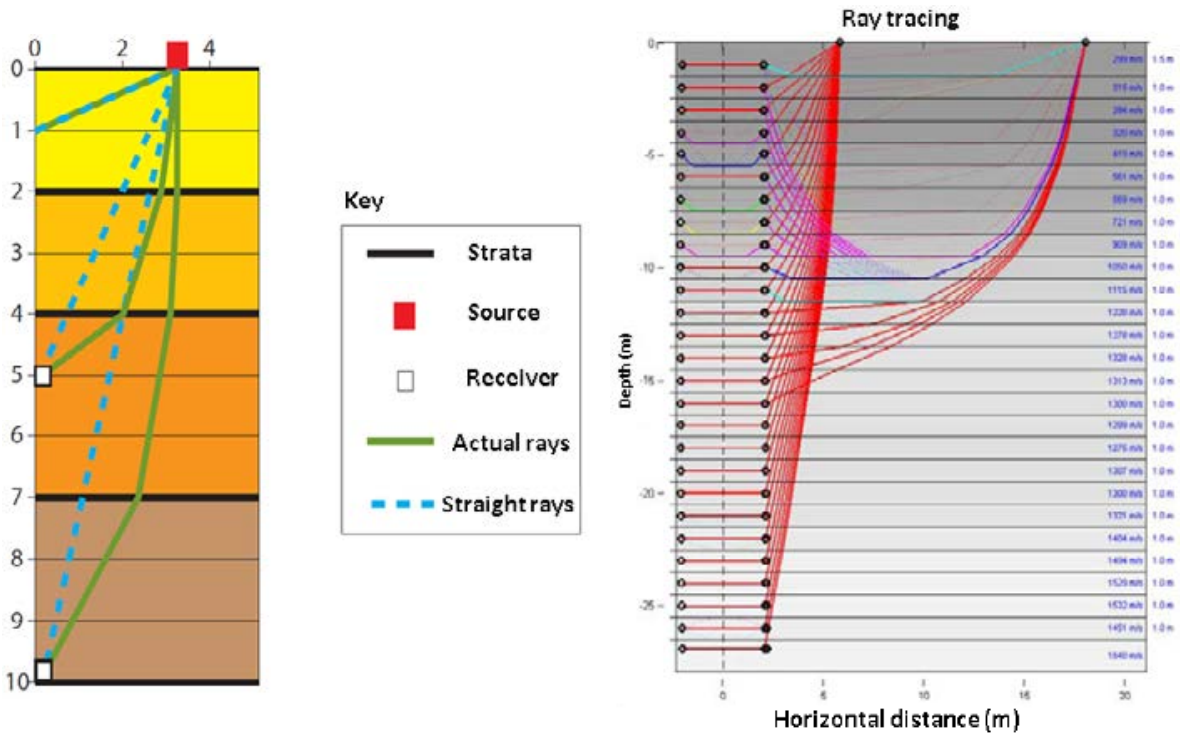

Figure 1.5 Illustration of the difference between actual path and straight rays in a classic downhole analysis (left). On the right, a ray model after joint inversion (Fugro for EDF) of a crosshole and 2 downholes with different offsets, illustrating that refracted waves are more present when the source offset is increased.

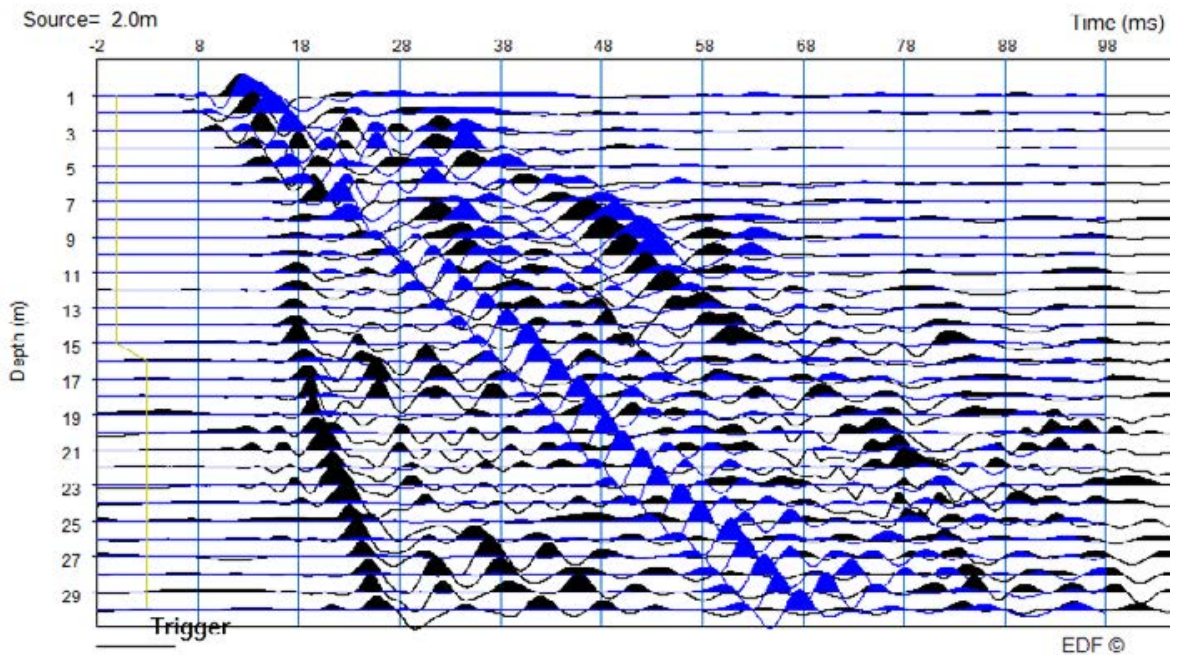

Figure 1.6 Illustration of a tube wave in a water-filled borehole. 
Figure 1.7 shows that air waves also exist in a borehole without water, but they are significantly less energetic ( $95 \mathrm{~ms}$ reflection at $30 \mathrm{~m}$ ). The effect can be reduced by placing a plug at the borehole head.

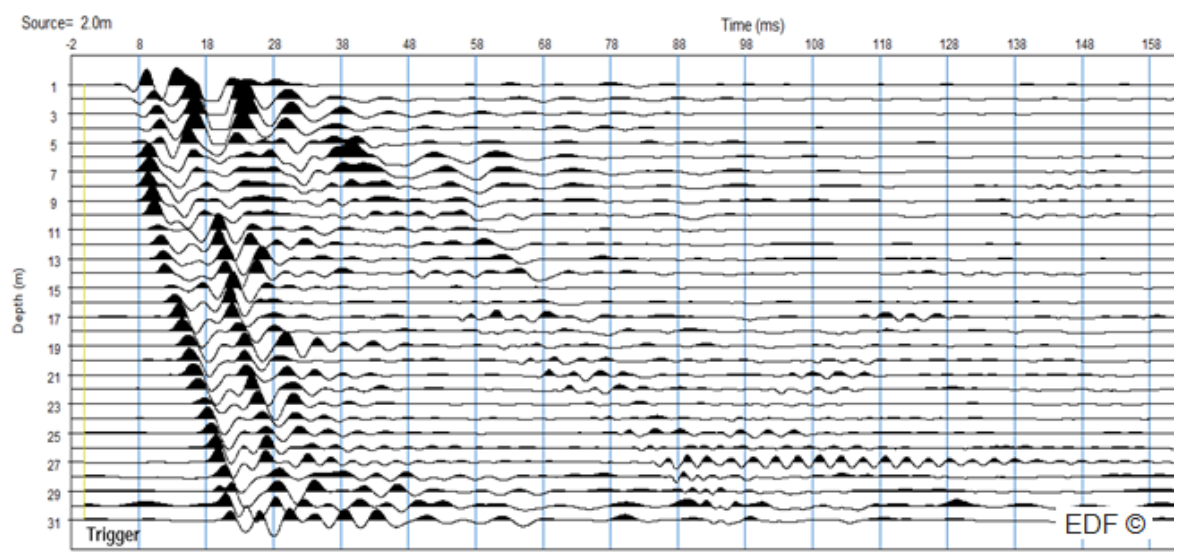

Figure 1.7 Illustration of a tube wave in a borehole without water.

Depending on the velocity of the medium, the tube wave in the water can mask $\mathrm{P}$ or $\mathrm{S}$ arrivals (see Figure 1.8). To avoid this it is essential to empty the borehole as much as possible or to increase the distance between the source and the borehole head. However, this last option will facilitate the generation of refracted waves (see Figure 1.5).
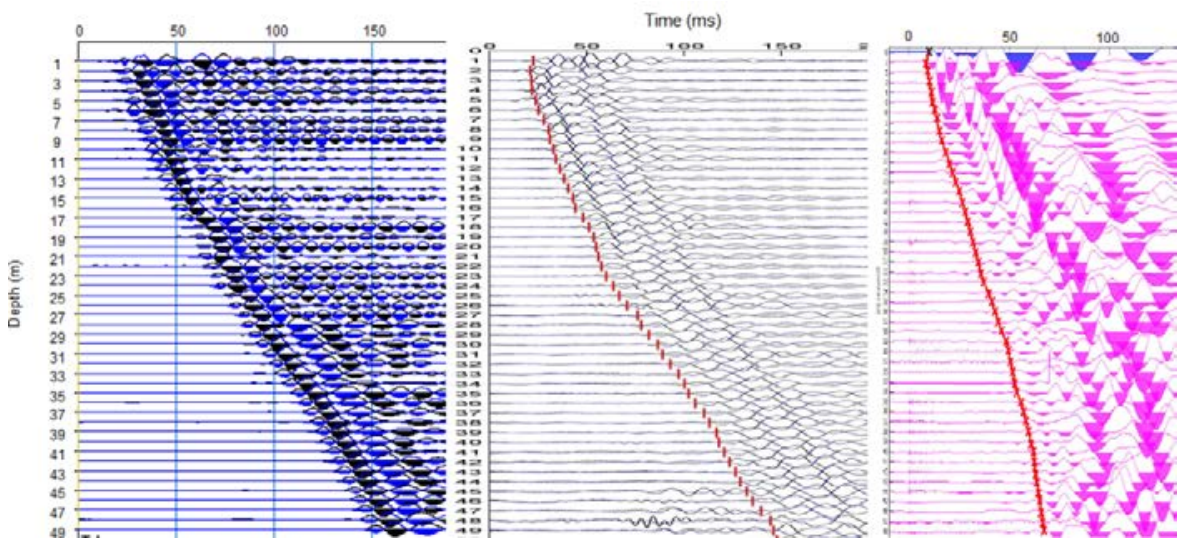

Figure 1.8 Illustration of tube wave impact (InterPacific Project), with a $3 \mathrm{~m}$ offset and borehole that has been emptied of water in the first example; with a $5 \mathrm{~m}$ offset and a borehole with water for the second example; and finally a third example showing a $3 \mathrm{~m}$ offset and borehole with water. This last example shows tube waves (InterPacific Project). 


\section{Seismic source coupling}

The coupling of the seismic source is also an important point (Figure 1.9). Ideally, the source should be positioned on natural ground (Figure 1.9a). In the presence of backfill, which strongly attenuates seismic waves (Figure 1.9b), it may be advisable to dig out the area until the natural terrain can be accessed. It should be noted that drilling and cementing techniques have a strong influence on signal transmission quality, as shown in the example in Figure 1.9c.
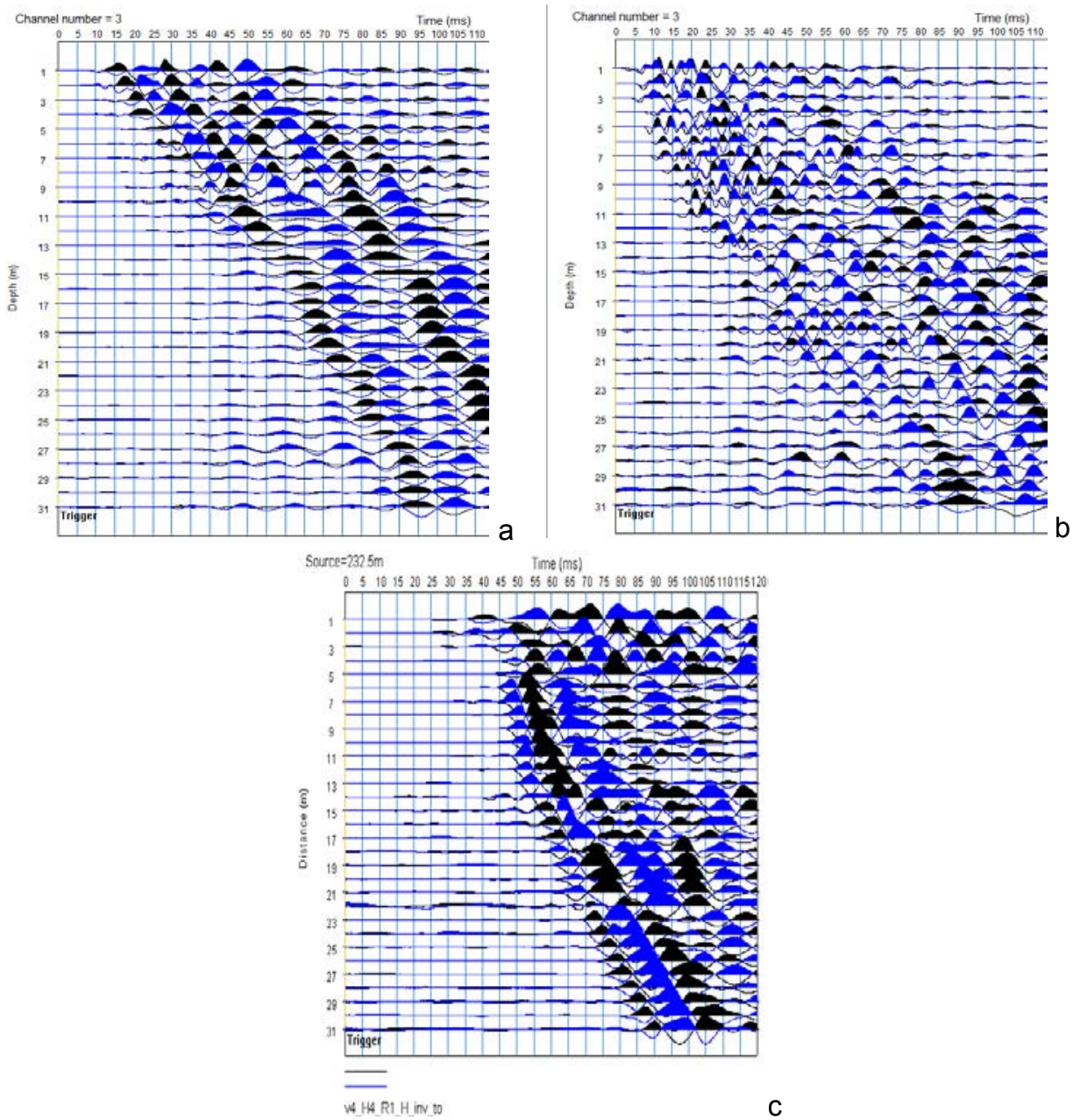

Figure 1.9 Effect of source coupling in downhole operation; a: Downhole with a source positioned on natural ground; b: Downhole with a source positioned on backfill (water table at $9.8 \mathrm{~m}$ ); c: Downhole on the same site as for a and $b$, but drilling carried out with sonic corer (4 $m$ water table, outside of water table the signal is polluted by refracted waves because the offset is too large). 
However, it is not always possible to situate the source on natural ground, but it is possible to make a short borehole to be able to use a borehole source directly under a backfilled area, in addition to that on the surface. However, it is important to use the surface source, because borehole sources are usually less powerful and there can be too much attenuation to make measurements for paths greater than $10 \mathrm{~m}$ (limitation on uphole measurement without the addition of a large number of stacks).

\subsection{Receivers}

In downhole surveys, P-wave energy arrives mainly on the vertical component of the receiver and $S_{H}$ wave energy is distributed on the horizontal components. Given that a short "offset" was applied (1 to $3 \mathrm{~m}$ ), it was necessary to pump the water out of the borehole to avoid tube waves. However, for a deep downhole, the casing should not be emptied to a depth greater than $50 \mathrm{~m}$, otherwise the risk of crushing the tube becomes too great. Consequently, it is not possible to use hydrophones near to the surface to make a P-wave downhole survey. A 3-component receiver anchored to the borehole wall, either a geophone or accelerometer type, is therefore recommended.

\subsubsection{Analysis of a downhole (DH)}

The initial step of the analysis involves picking the first $\mathrm{P}$ and $\mathrm{S}$ arrivals. A good quality signal will ensure that $\mathrm{P}$-waves can be picked without difficulty. For S-waves, it is essential to exploit the polarization property of the wave according to the direction of the strike (Figure 1.10). For this purpose, the phase opposition of shots in the opposite direction makes it possible to unambiguously identify $S$ arrivals (blue and black signals are of opposite sign, in Figure 1.10). Without this opposition, the recorded signal should be viewed with caution, because it may translate tube wave pollution or P-wave interference.

Figure 1.10 illustrates that with a conventional source, the phase opposition characterizing the $S$-waves can be observed down to $50 \mathrm{~m}$ deep. In favorable terrain, the same types of signals are observed down to a depth of $100 \mathrm{~m}$.

As with seismic refraction, the first step of the analysis is to view the distance-time graph (source-receiver distance curve as a function of time). In the first 10 meters this curve differs significantly from the depth-time curve due to the offset of the source (see Figure 1.5). At this point, the path between the source and the receiver is considered linear. However, this approximation is false if the medium has noticeable velocity variations in the first 10 meters. The impact increases with the offset of the source. From the distance-time graph, a downhole analysis is carried out in depth ranges (slices). The division into slices must be related to the slope break on the distance-time graph, but also and especially in connection with the geological log obtained from cores.

On the slices thus defined, the slope between the variations of distance and time of each segment provides the average velocity over the corresponding interval (see Figure 1.11). The slope of the radius linking a point to the origin gives the average velocity of the ground at the corresponding depth. Due to the picking uncertainty, 
each slice must contain a minimum of 3 measurement points, ideally 4 or 5 (see Figure 1.12). As a result, it is not recommended to carry out downhole acquisition with 2 receivers simultaneously to perform velocity calculations based on these 2 measurements. Finally, we also note that a downhole analysis, even with a metric measurement interval, is more integrative than a crosshole measurement.

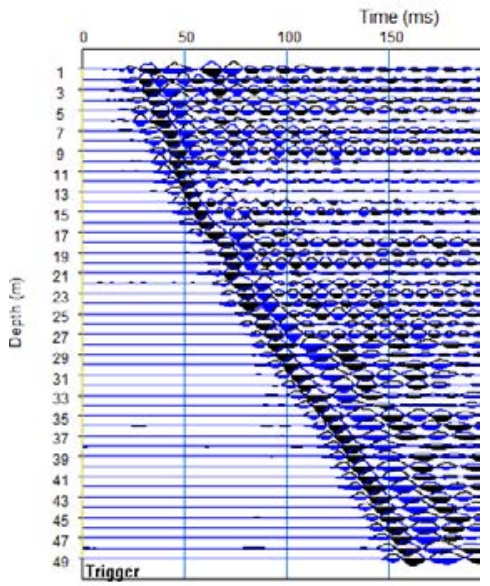

Figure $1.10 \mathrm{~S}$ downhole, up to $50 \mathrm{~m}$ in depth (InterPacific).

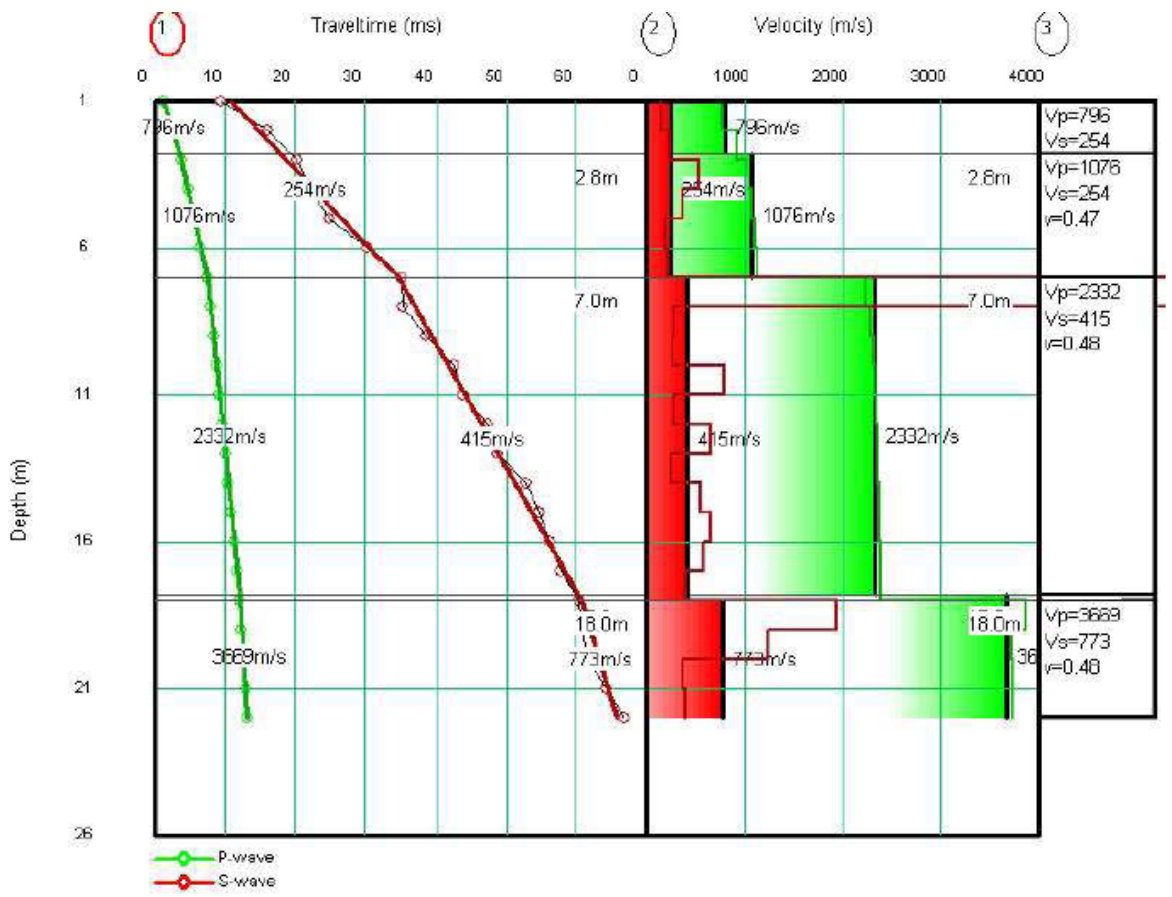

Figure 1.11 Illustration of a downhole (DH) analysis in P and S-waves based on 4 slices. 

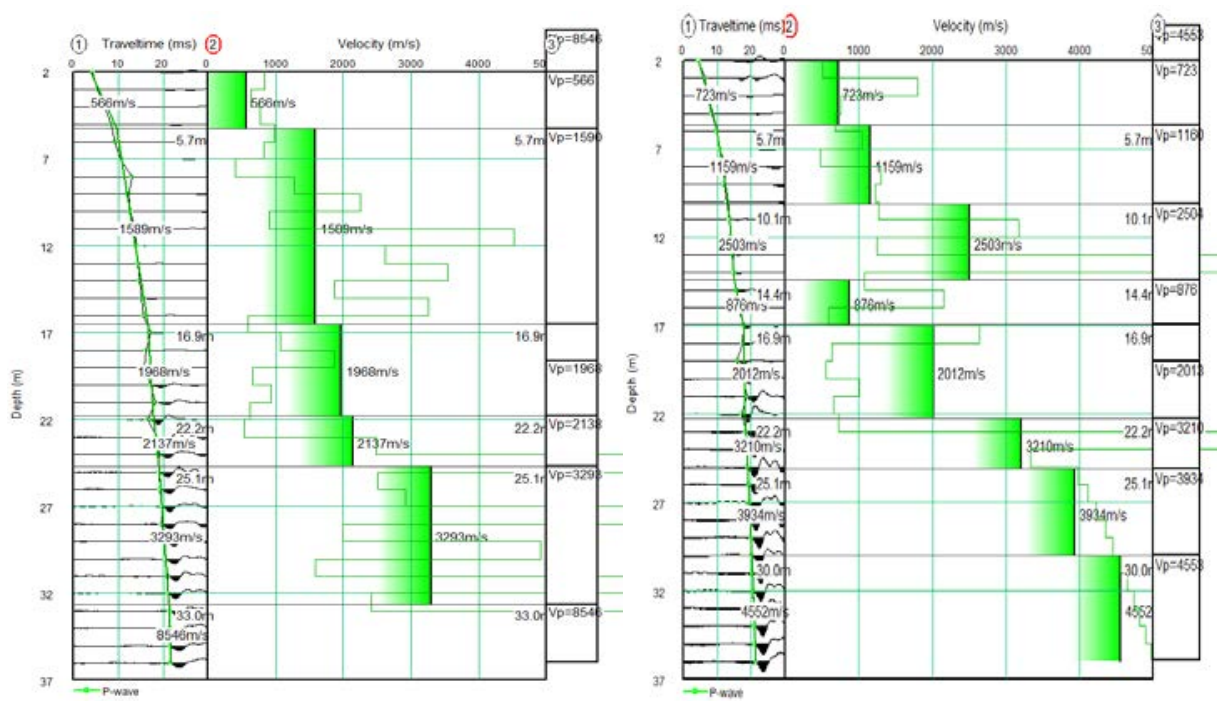

Figure 1.12 Illustration of the sensitivity of the analysis of the same Downhole (DH) according to slice selection.

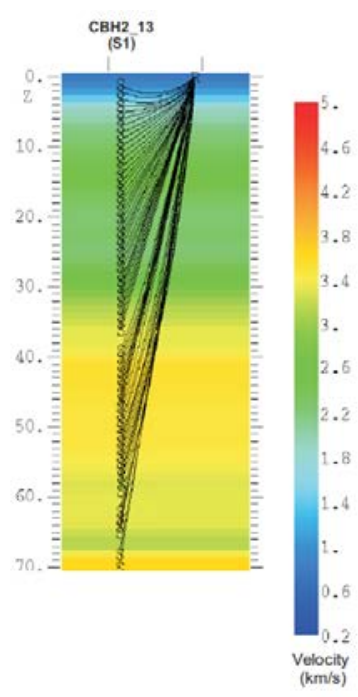

Uphole P-wave tomogram (8m offset)

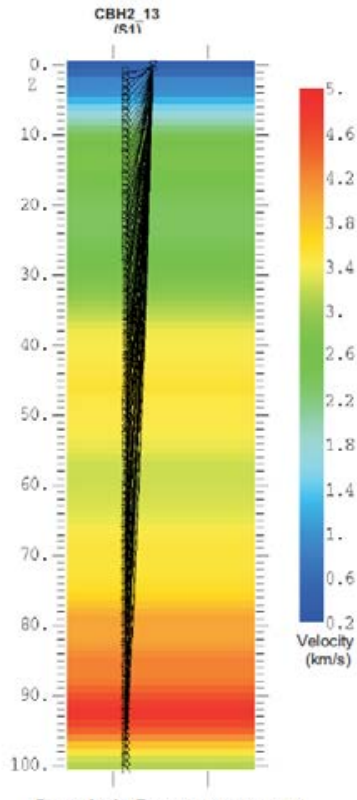

Downhole P-wave tomogram ( $3 \mathrm{~m}$ offset)

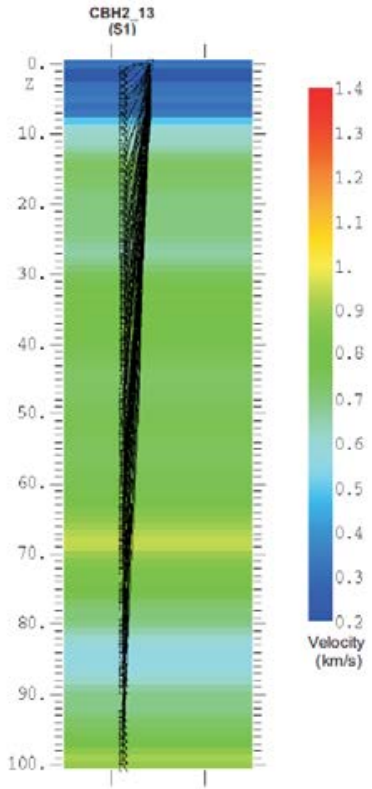

Downhole Sh-wave tomogram ( $3 \mathrm{~m}$ offset)

Figure 1.13 Uphole and downhole result after inversion with GEOTOMGC software (Terradata for EDF). 
To ensure the reliability of the analysis for the first 10 meters, a direct modeling or iterative inversion approach is possible (Figure 1.13). That is to say that, the direct calculation of travel times, for a given velocity model, must integrate the direct and refracted paths. Then, depending on the difference between the measured times and the calculated times, the model is adjusted. This iteration is repeated until the error criterion is acceptable.

Currently, software packages available on the market are not optimized for borehole measurements and do not directly differentiate between direct and refracted waves but take straight and curved raypaths into account. The straight rays correspond to the transmitted travel paths and the curved rays to the refracted waves.

\subsubsection{The specific example of offshore}

It is possible to carry out a $\mathrm{P}$ downhole survey at sea in an uncased borehole, using a source such as an air gun or sparker near to the surface. It is, however, much more complicated to find an $S$ source that is operational underwater and a 3-component receiver. Finally, if the ground is unstable, a P downhole survey through an unsealed protective casing can work if the terrain crossed is sufficiently plastic to establish an acceptable coupling with the casing (see Figure 1.14).
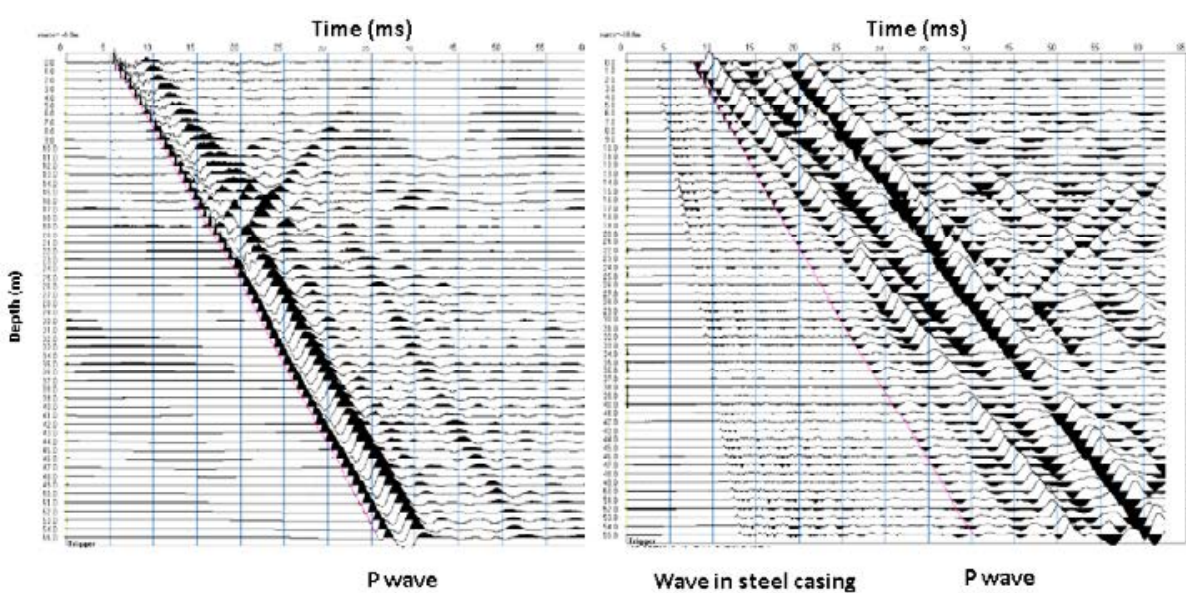

Figure 1.14 Downhole at sea in an uncased hole and through an unsealed protective casing (Fugro for EDF). 


\subsubsection{Uphole}

An uphole is similar to a downhole, but with the source in the borehole and the receiver on the surface. The practice is more limited because $S$ sources in boreholes generate a signal that fades over a relatively short distance. Even for P-waves, with a relatively powerful source (sparker) it is necessary to perform a large number of stacks. However, Figure 1.13 shows that depending on the context it is possible to obtain interesting results with P-waves (left graph). In addition, it can be useful to carry out an uphole when the measurement is coupled to crosshole acquisition, because this only requires the addition of a 3-component receiver on the surface.

\subsubsection{Crosshole}

The principle consists of measuring the travel time of compressional and shearing seismic waves, transmitted directly between a seismic source in a borehole and a 3 -component receiver in a neighboring borehole.

The compressional wave $(\mathrm{P})$ propagates through the horizontal plane as well as the horizontal component of the shear wave $\left(\mathrm{S}_{\mathrm{H}}\right)$. The vertical component of the shear wave $\left(S_{V}\right)$ propagates in the vertical plane. Therefore, the energy of the $P$ and $S_{H}$ wave is mainly distributed on the horizontal receivers and that of the $S_{v}$ wave on the vertical receiver.

The result of a crosshole measurement is often blindly accepted as a reference, but the method can face the following limitations, it can:

- be strongly affected by refracted waves in surrounding indurated strata,

- present "spatial aliasing" if bed thickness is less than that of the intervals,

- be affected by highly inclined formations,

- be strongly affected by poor cementation (casing-sealant-formation connection),

- be strongly affected by damage in the vicinity of the borehole.

Consequently, it is recommended to perform a downhole and/or uphole recording to complete and validate the crosshole, assuming that the anisotropic attenuation is negligible.

Specific cases:

- With highly heterogeneous geology, only seismic tomography can provide reliable information for the $\mathrm{P}$-wave profile. Therefore, in an environment with a known heterogeneous nature, it is also recommended to carry out an additional $\mathrm{P}$ crosshole acquisition with a hydrophone array so as to exploit the tomography data. For $S$-waves, the implementation of more than 2 anchored sensors is complex in the geotechnical field and therefore downhole or uphole recording generally has to suffice.

- Similarly, if the test is carried out in an environment with high horizontal anisotropy (e.g. beds fractured in a certain direction), the measurement system and 
results interpretation must be adapted (receiving boreholes at $90^{\circ}$ with directions parallel and perpendicular to those of the anisotropy).

- Finally, if the test is carried out in a medium with strong vertical anisotropy related to thin beds, the measurement system must also include a specific $\mathrm{S}_{\mathrm{H}}$ source (sparker $\left.\mathrm{P}-\mathrm{S}_{\mathrm{H}}\right)$.

\subsubsection{Prerequisites}

The quality of the casing sealing has a much stronger impact on the crosshole measurement than it does on the downhole measurement, because the signals are of higher frequency.

Velocity calculation requires the precise knowledge of the distance between the boreholes. Human error is possible with inclination measurements (see Figure 1.15) and a calibration defect can affect the trajectory measurements (see Figure 1.16). It is therefore vital to apply a procedure on the surface to control for the directions given by these measurements.
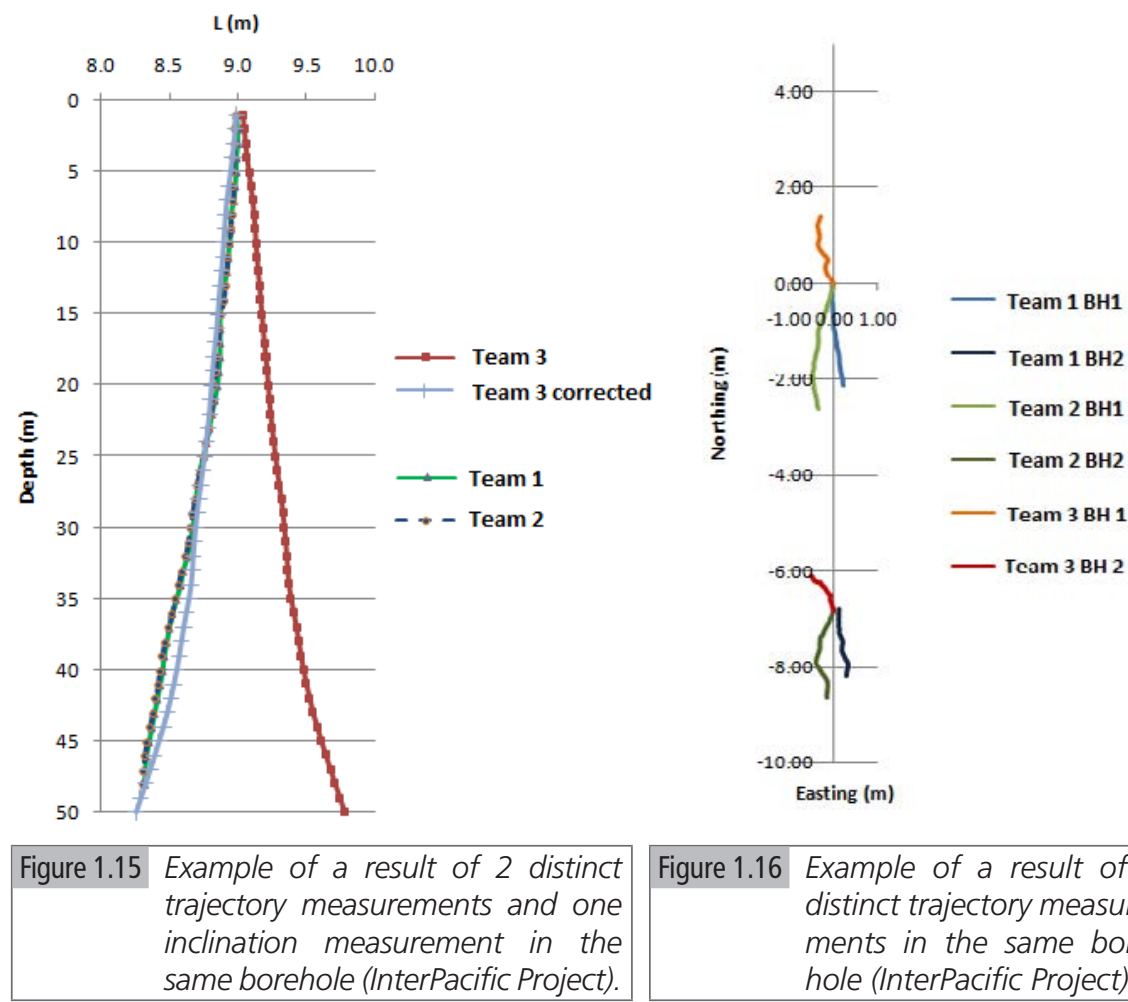
Figure 1.16 Example of a result of 3 distinct trajectory measure- ments in the same bore- hole (InterPacific Project).




\subsubsection{The acquisition device}

It is necessary to dissociate the acquisition and the analysis of the compression (P) and shear (S) waves. Until the start of the 1980s (Figure 1.17), the crosshole test was carried out as the source moved forward by striking the head of the drill string. This method has evolved through the development of an emission probe pressed against the borehole wall. This has the major advantage of separating the activities of the borehole drilling group from those of the geophysics measurements team. However, this brings source coupling problems.

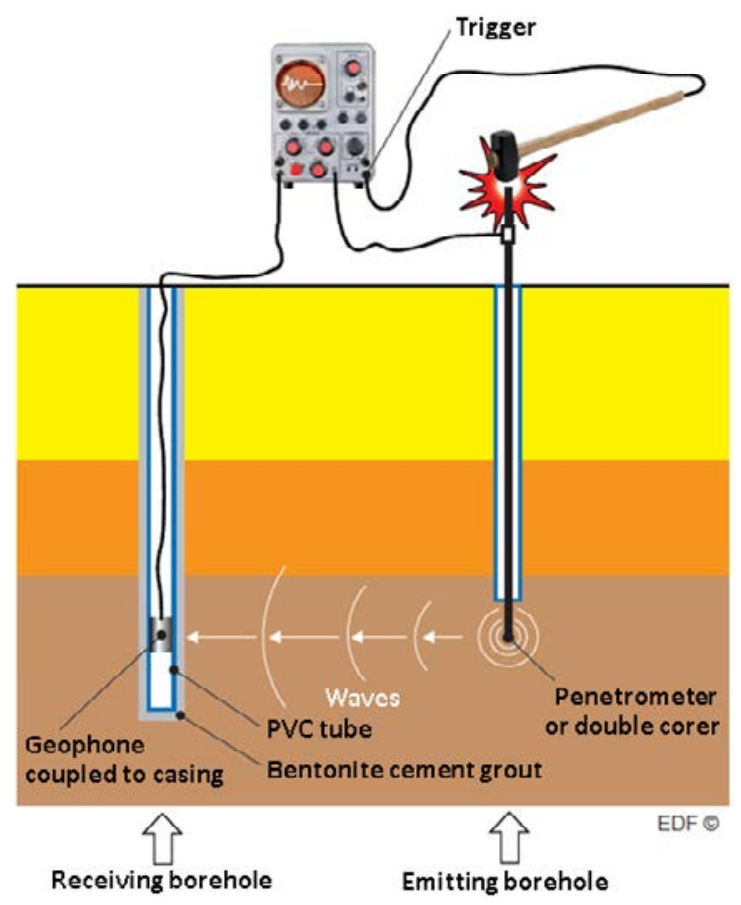

Figure 1.17 Historical crosshole measurement method, applied in France until the beginning of the 1980s.

The typically recommended crosshole method (Figure 1.18) requires 3 boreholes to calculate the velocity between two receiving boreholes without needing precise knowledge of the wave generation time ( $\mathrm{t} 0$, zero time). Today, this approach is questionable because very often the attenuation is such that the signal of the second borehole is difficult to exploit, and also the shot recording is no longer a technical limitation. Nevertheless, working with only one receiving borehole requires greater rigor, in particular, a calibrated measurement chain is required. As an example, there can be drift between the electric impulse and the generation of a sparker signal (Figure 1.19) due to the wearing of electrodes. 


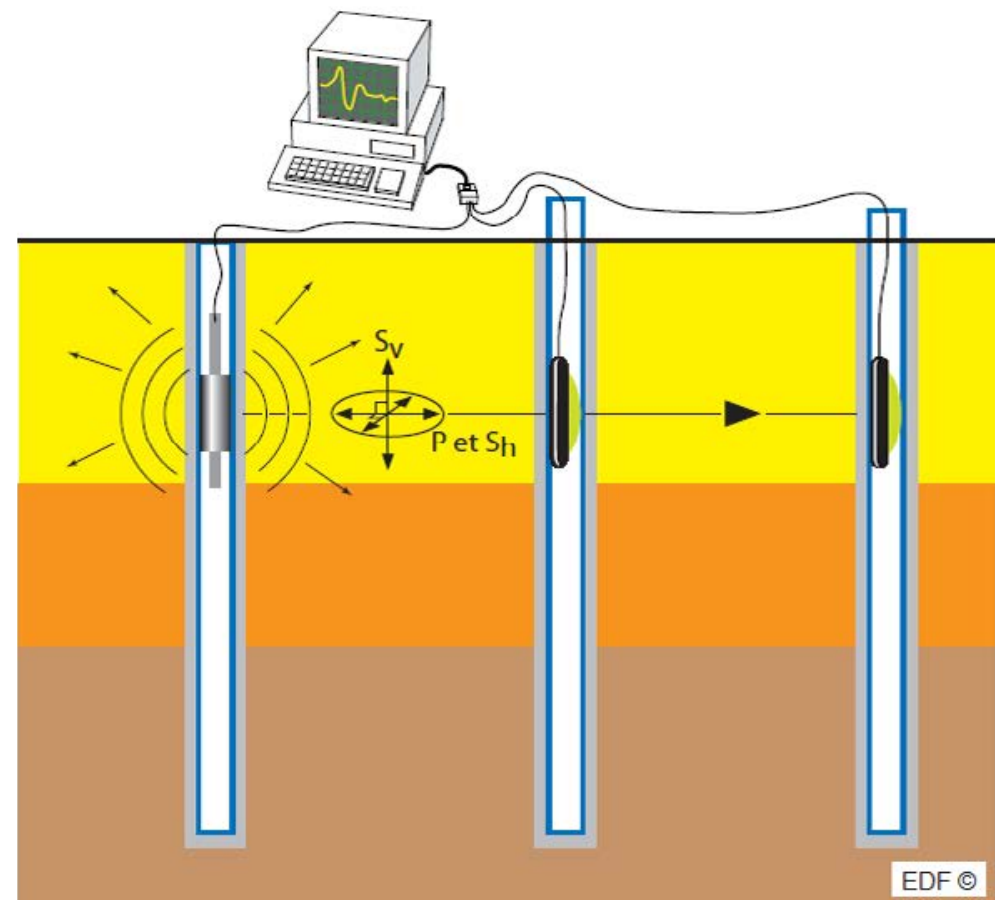

Figure 1.18 Illustration of a 3 borehole crosshole system.
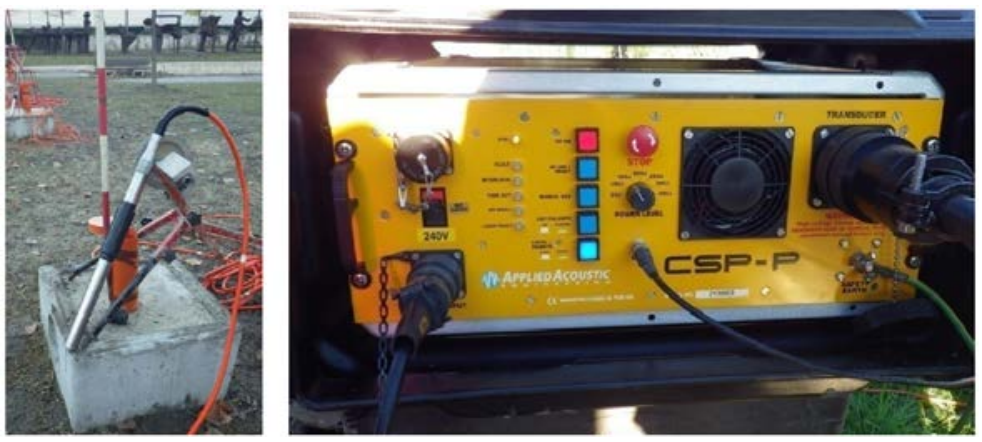

Figure 1.19 Illustration of a $P$ source: sparker (So/Géo).

Moreover, having a single receiver borehole can be disadvantageous if we want to pick the first arrival time at the maximum wave amplitude (apex), rather than at its beginning. Admittedly, this technique makes it possible to work with signals with a signal-to-noise ratio that is not so good. Moreover, due to the signal attenuation, 
too much noise can make it difficult to identify the start of the wave, which is the case particularly with the signal in the most distant borehole.

\subsection{Sources}

To maximize the energy of shear waves, it is recommended that a source that is mechanical (hammer-anvil) or electromechanical (similar to the sources of the PS Suspension Logging (PSSL) tool) should be anchored to the wall (Figure 1.20).
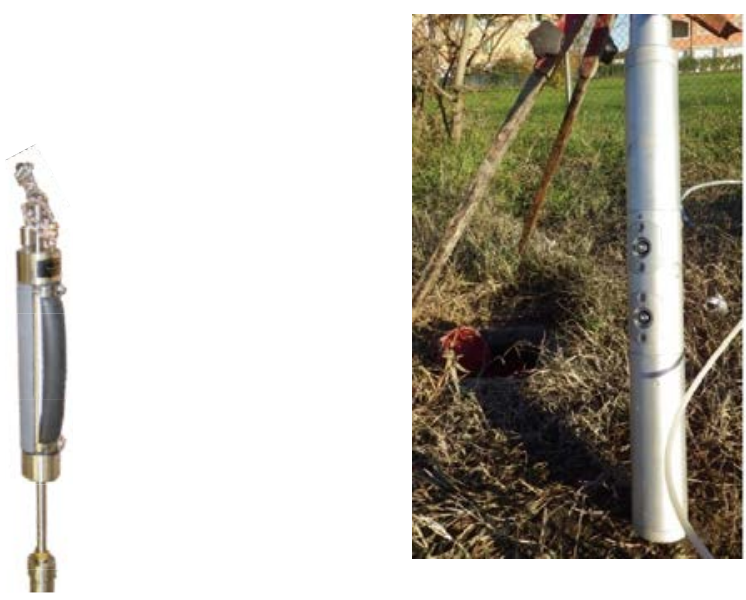

Figure 1.20 Illustration of a mechanical (Ballard anvil hammer) and an electrodynamic (SolGeo, mass moved up or down by an electromagnet) $S$ source.

\subsection{Receivers}

For P-waves, energy is distributed over the horizontal components, which can generate difficulties in picking the first arrivals and requires a mathematical polarization operation to project the energy in the source-receiver direction. Some receivers can be oriented in a given direction. However, the most simple and robust method is to use hydrophones to measure the P arrivals. It should be noted that some hydrophones are directly equipped with an amplification system to optimize recording dynamics.

For S-wave analysis, only a single 1-component receiver is needed. However, having a 3-component receiver associated with the mechanical source makes it possible, if required, to verify $\mathrm{P}$ measurements with the sparker-hydrophone combination (Figure 1.21). 

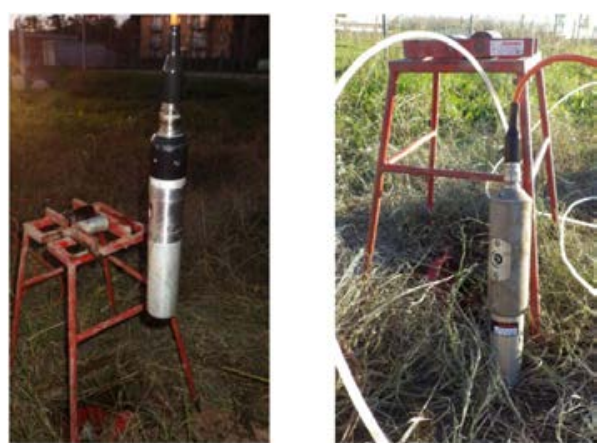

Figure 1.21 Hydrophone with an amplification system and 3C geophone with an anchoring system (Solgéo).

\section{Sampling}

Crosshole data acquisition requires small time sampling intervals.

$50 \mu$ s sampling is acceptable for recording S-waves, whereas higher frequency P-waves require a faster sampling rate until $2.5 \mu$ s (Figure 1.22).
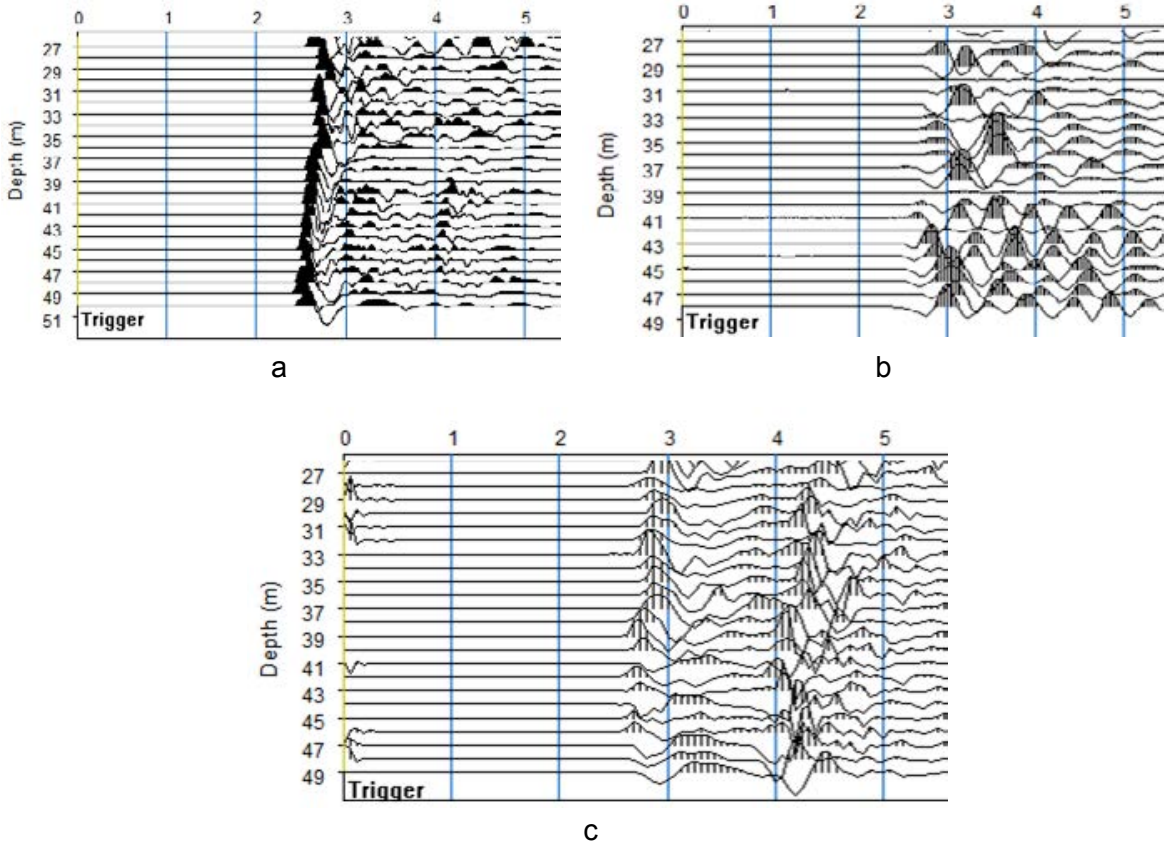

Figure 1.22 $P$ recording in the same borehole with a sampling rate of (a) 2.5, (b) 32.25 and (c) $62.5 \mu \mathrm{s}$. 


\subsubsection{Crosshole analysis}

At first glance crosshole analysis appears simple and robust, and only requires the picking of the first arrival of the selected wave ( $\mathrm{P}$ or $\mathrm{S}$ ), and to divide this travel time by the distance between the source and the receiver, to obtain the velocity of the medium. However, several cautionary notes, described below, should be considered.

As discussed in the section about receivers, $\mathrm{P}$ interpretation using geophones requires the polarization of horizontal traces to optimize the signal amplitude. However, sometimes the result of this operation is less clear than when looking at the results of one of the two components, and sometimes the operation is complex, such as when the receiver has six horizontal components.

Moreover, in alluviums, particularly outside of the water table, sometimes the attenuation of $\mathrm{P}$-waves is such that they are no longer distinguishable from noise. Two causes explain this problem:

- Firstly, drilling and cementing are delicate in this type of terrain and the result of cementing can be highly variable according to the drilling technique used. For this type of terrain there is a risk of forming a thick cement annular that does not adhere to the formation, which can create a waveguide that filters $\mathrm{P}$-waves more than $\mathrm{S}$-waves, because they are of higher frequency (often $1,000 \mathrm{~Hz}$ compared to $200 \mathrm{~Hz}$ ). To limit this effect, the use of a sonic corer is recommended, to avoid destructuring the terrain.

- Secondly, the mechanical source generates insufficient P-wave energy for this type of very attenuating terrain, so a more powerful $\mathrm{P}$-wave source, such as a sparker, should be used.

Figure 1.23 illustrates the above comments. The two crossholes were made in distinct sites, but both had sandy-gravelly alluvial cover down to $22 \mathrm{~m}$ and $21.6 \mathrm{~m}$ respectively, over a clay or marly substratum.

In both cases, there is a change in the frequency content between the alluvium (low frequency signal) and the substratum (high frequency signal). However, in the second case the first identifiable arrivals in the first 19 meters are not P-waves, because the times correspond with those of the $S$-waves probably picked on the horizontal components. On the other hand, in the first case it is possible to identify $\mathrm{P}$ arrivals over the entire depth.

Attenuation mainly affects distant receivers in crossholes with several receiving boreholes. This justifies making an acquisition with a specific $\mathrm{P}$ source that is more powerful than a mechanical source, which is made to maximize the energy of the S-waves. In addition, it is entirely possible to limit the crosshole to two boreholes, but only on the condition that the results are consistent with those of a downhole and/or uphole made in one of the two boreholes.

The crosshole method can also be affected by refracted waves (especially when the offset is greater than $6 \mathrm{~m}$ ). The example presented in Figure 1.24 illustrates that it 
is possible to detect refracted waves and confirm their existence solely based on the visual analysis of the signals, crossed with the information from the cores.
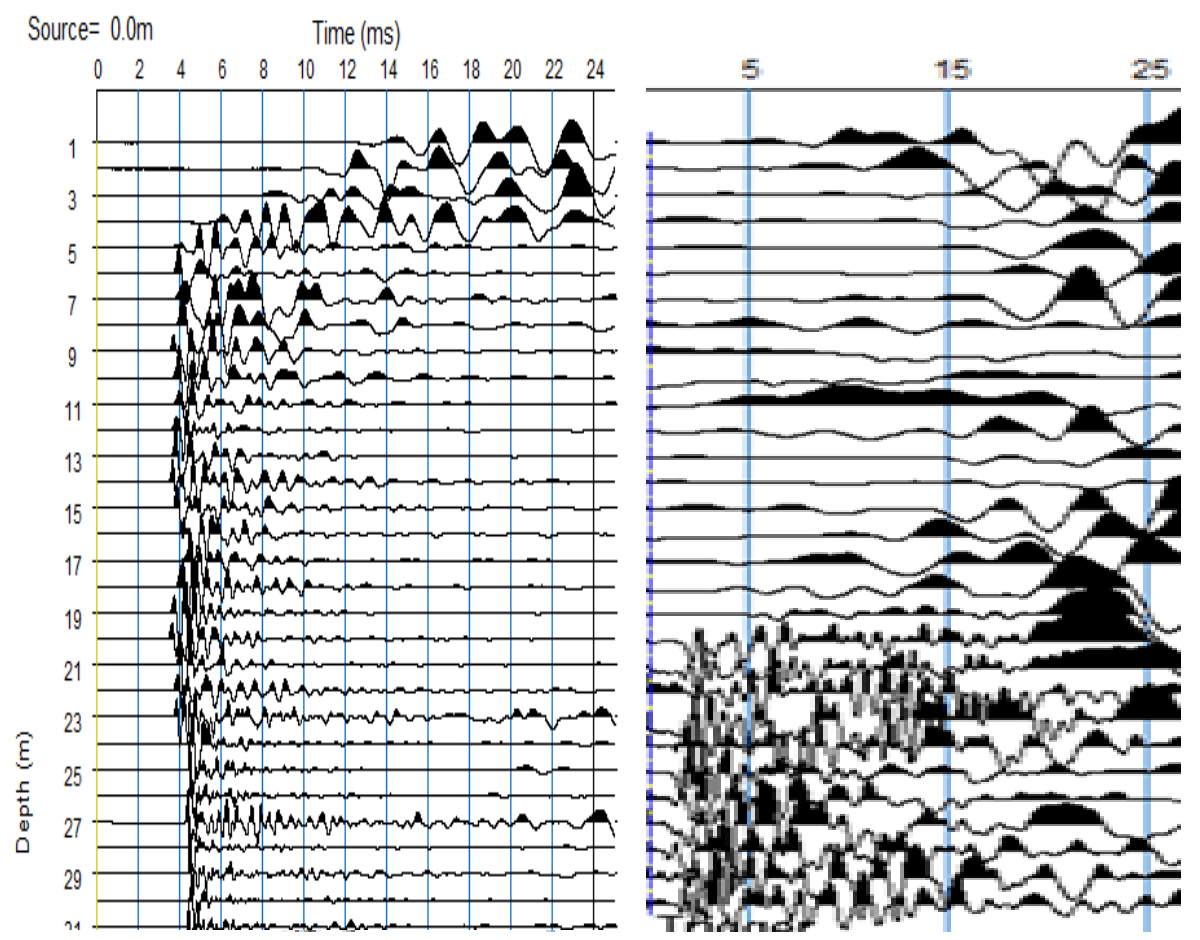

Figure 1.23 Examples of crosshole recording. a) left, $P$ Crosshole (InterPacific, water table at $3 \mathrm{~m}$ ), b) right EDF site (water table at $6 \mathrm{~m}$ ).

On the S-wave crosshole recording, on the left of Figure 1.24a, there is a fast S first arrival at 22 and $23 \mathrm{~m}$ in depth (shown in red). At greater depths, this $S$ arrival is later. There are therefore two areas for which $S$ velocities can be calculated at 500 and $260 \mathrm{~m} / \mathrm{s}$ (see velocity model on the right). Directly under the fast formation, at 24 and $25 \mathrm{~m}$ deep, we observe a first arrival with little energy (shown in green). This is a refracted arrival, with the transmitted arrival (shown in red) keeping the same phase. The phenomenon can be explained by calculating the distancetime graph for example at $2 \mathrm{~m}$ from the interface between the two media (i.e. $25 \mathrm{~m}$ deep, see Figure 1.24b). Figure 1.24b shows that at the distance of the first borehole $(\mathrm{X}=3 \mathrm{~m})$ the direct wave (P: solid blue line, $\mathrm{S}$ : solid green) arrives first, while in the second borehole $(\mathrm{X}=6 \mathrm{~m})$ it arrives after the refracted wave (blue dotted line for the $\mathrm{P}$-wave and green for the $\mathrm{S}$-wave). By carrying out this analysis at depths of 24 and $26 \mathrm{~m}$, we can then draw the fastest paths, which are illustrated by the green arrows on the left of Figure 1.24a. 


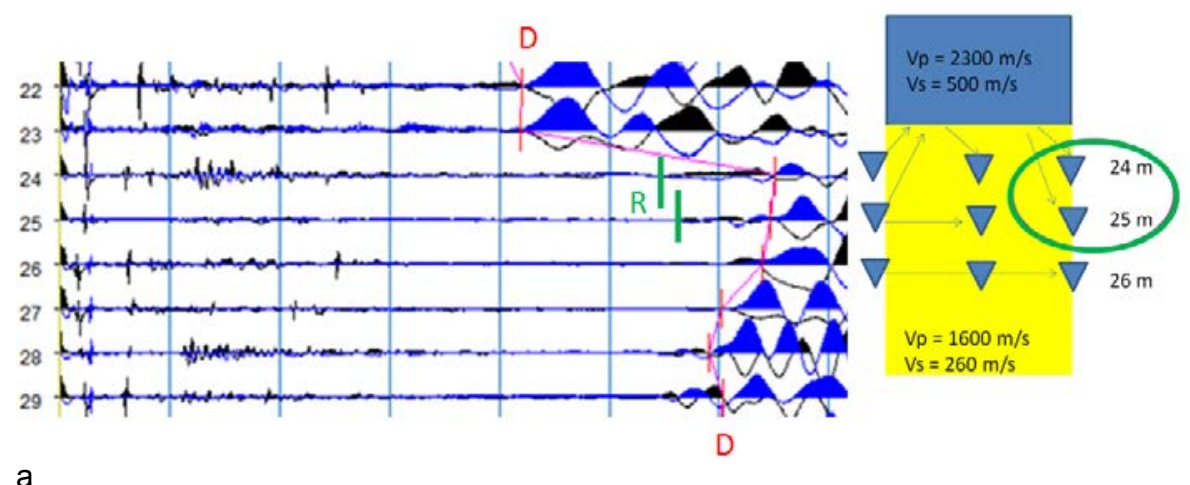

\section{Travel time curve of a crosshole}

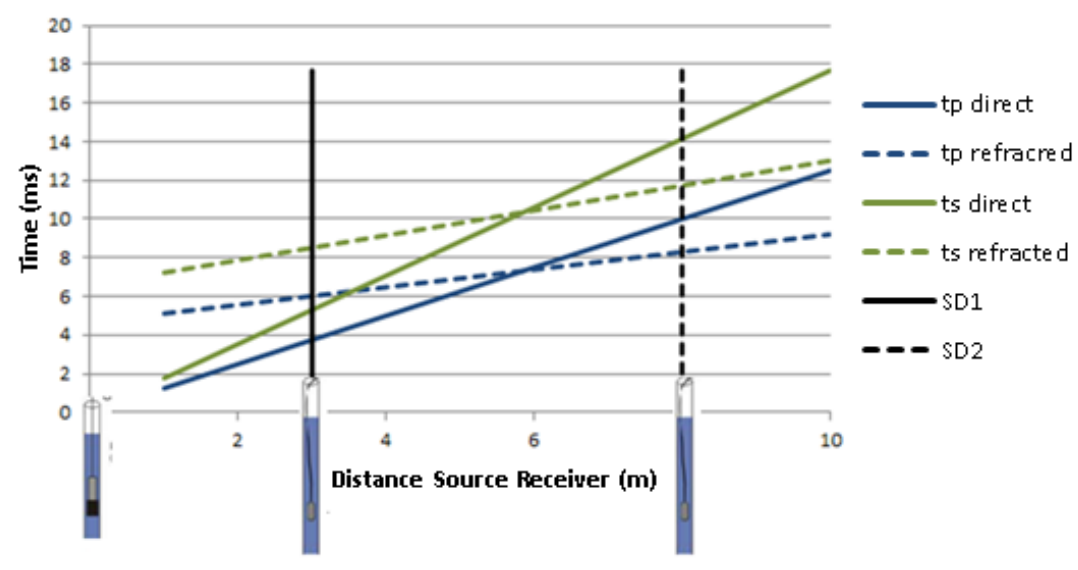

Figure 1.24 Crosshole examples; a: left, S recordings between 22 and $29 \mathrm{~m}$ in depth and, right, associated geological model; $b$ : $P$ and $S$ time-distance curve, with a measurement level at $2 \mathrm{~m}$ from the interface with a faster strata (based on the bottom right model).

The above approach requires time and experience. It is therefore difficult to generalize to apply to all applications. The ASTM standard recommends the implementation of a computer analysis to take into account the different possible paths (inversion). In practice, this was not carried out in France, but has started to be used since 2015.

Figure 1.25 shows an example of tomography results obtained with inversion software. 


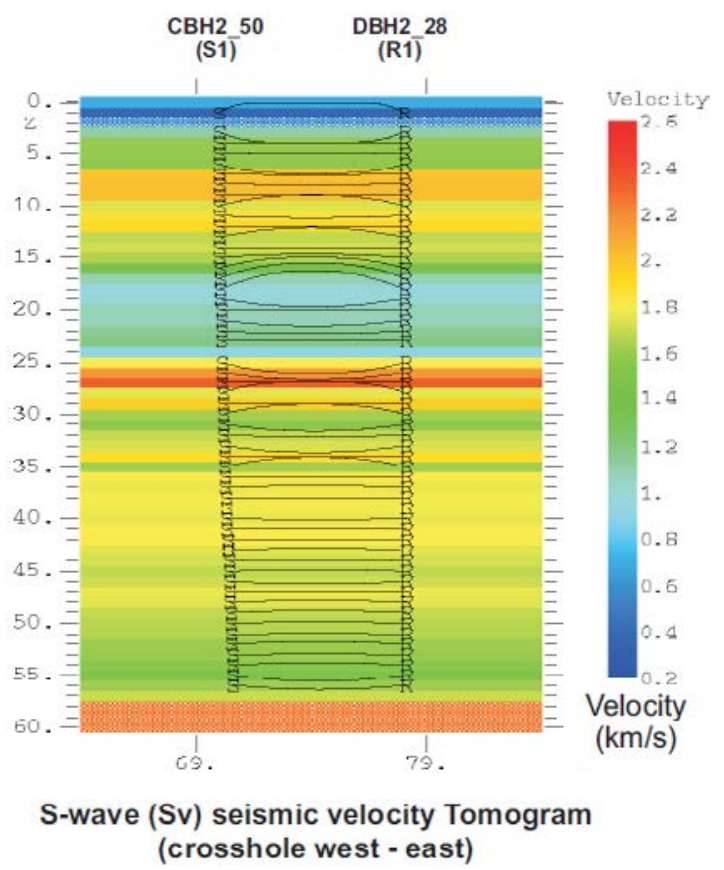

Figure 1.25 Crosshole result after inversion with GEOTOMGC software (Terradata for EDF).

\section{$1.3 \quad \mathrm{~V}_{\mathrm{s}}$ measurement by logging}

\subsubsection{Acoustic logging with high vertical resolution}

In geotechnology, the logging tools that can be used are generally of a small diameter $(<50 \mathrm{~mm})$ and non-stackable, as is practiced in the field of oil exploration. The conventionally used acoustic probes are therefore short probes $(3.5 \mathrm{~m})$, composed of a high frequency monopole-type piezoelectric transmitter (10 to $40 \mathrm{kHz}$ ) (see Chapter 3). It is important to remember that this means that the source is omnidirectional and that it generates $\mathrm{P}$-waves in the fluid. These waves are refracted $(P, S)$ at the level of the borehole wall and guided modes also appear. These are, in particular, Rayleigh waves for a solid-air interface and the Scholte-Stoneley wave for a solid-fluid interface. Therefore, the existence of refracted shear waves implies that the $\mathrm{P}$ velocity of the fluid is lower than the $S$ velocity of the formation for an uncased borehole. $V_{s}$ measurement with acoustic logging is therefore recommended for fast formations. 
When the formation is slow $\left(\mathrm{V}_{\mathrm{s}}\right.$ formation $<\mathrm{V}_{\mathrm{p}}$ fluid), the Scholte-Stoneley waves can enable the estimation of $S$ velocities with an acoustic tool. It is nevertheless necessary to occasionally have the means of tying the conversion between the Scholte-Stoneley velocities and the shear velocities (for example, a downhole log with multi-metric measurement levels).

Figure 1.26 is an example of Full Wave Sonic (FWS) logging obtained with a monopole tool. On the right the figure shows the acoustic section obtained with a sourcereceiver offset of $4 \mathrm{ft}$ and on the left the velocity logs of the different wave trains (P refracted, $\mathrm{S}$ refracted and Stoneley).

\begin{tabular}{|c|c|c|c|c|c|}
\hline & $v_{p}$ & & Depth & 4FT & \\
\hline 0 & $\begin{array}{l}\mathrm{m} / \mathrm{s} \\
\mathrm{vs}\end{array}$ & 5000 & $1: 200$ & $\mu s$ & 3995 \\
\hline 0 & $\begin{array}{l}\mathrm{m} / \mathrm{s} \\
\mathrm{Vst}\end{array}$ & 5000 & & & \\
\hline 0 & $\mathrm{~m} / \mathrm{s}$ & 5000 & & & \\
\hline
\end{tabular}

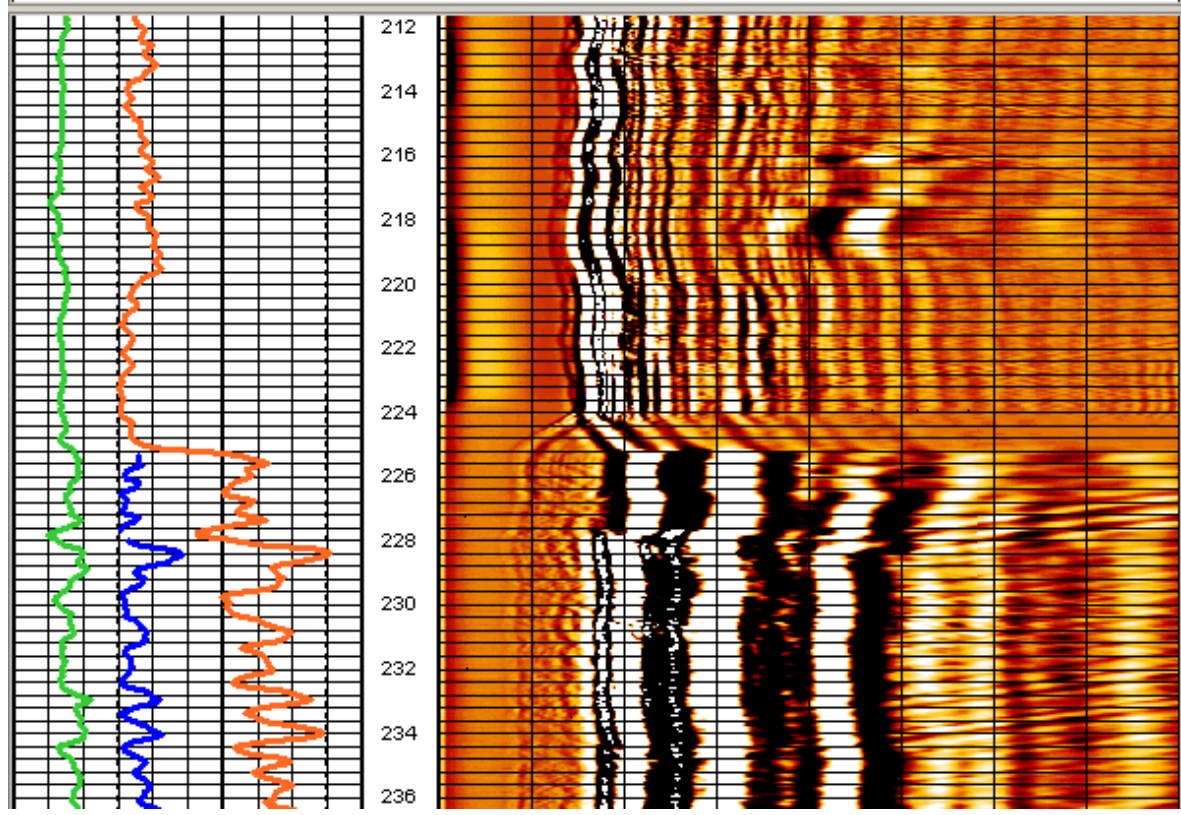

Figure 1.26 Example of sonic FW recording (monopole), showing a low energy $P$ first arrival, for which the arrival time decreases significantly after $225 \mathrm{~m}$ (entry into the rock), the S arrival is only visible below $225 \mathrm{~m}$ where the medium has a velocity that is considered as fast compared to the mud (rock) [SEMM logging for EDF]. 
In slow formations, the measurement of $S$ velocities cannot be obtained by using monopole-type tools. The oil industry has developed dipole-type tools including polarized transmitters and receivers that generate and record bending waves, the propagation velocity of which is close to the $S$ velocity of the formation (see Chapter 3). The problem is that these oil industry tools are rigid and very long. However, a flexible alternative exists for the geotechnology field: PSSL.

\subsubsection{PS Suspension Logging (PSSL)}

PS Suspension Logging (PSSL) is a flexible logging probe for non-continuous measurement with an electromechanical drill source and two receivers (see Chapter 3).

It should be noted that the frequencies used by the PSSL enable measurements to be made in boreholes with PVC casing. Seismic wave velocities are calculated from the difference between the arrival times between the two receivers (Near and Far) spaced $1 \mathrm{~m}$ apart. As a result, the tool needs to be centered in the borehole, but since it is flexible (see Figure 1.27) and it is difficult to find centering rings that are adapted to the borehole, this is not always possible.

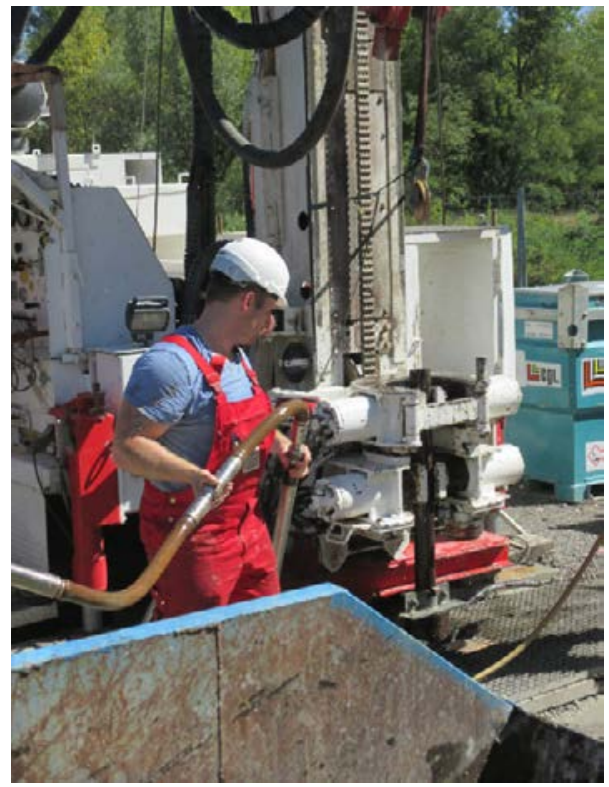

a

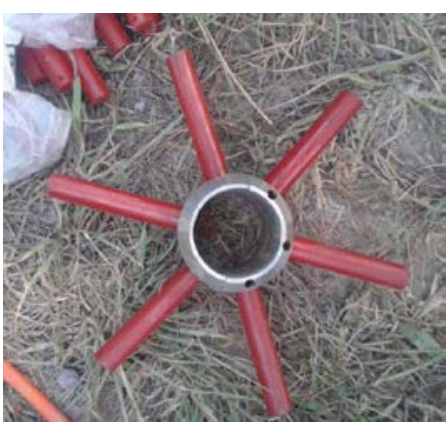

b

Figure 1.27 PSSL tool a) set up of a PSSL tool with a continuously active drill rig (Fugro for EDF), b) typical centering ring component of PSSL tool. 
However, in a vertical borehole, all logging tools rotate during the ascent and when the wall is inclined, they clamp onto the lower part of the wall. In addition, when a borehole is inclined, there is typically a scraping of the formation related to the friction of the drill string (reaming) and this implies anisotropy of the thickness of the cement grout around the casing. In Figure 1.28, this may account for the differences observed between PSSL and downhole measurements between 75 and $120 \mathrm{~m}$ deep, particularly at the level of the clay formation at $75 \mathrm{~m}$, which is typically favorable to the development of "caves".

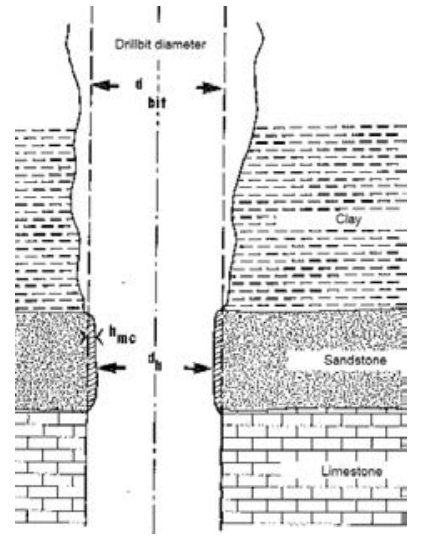

a

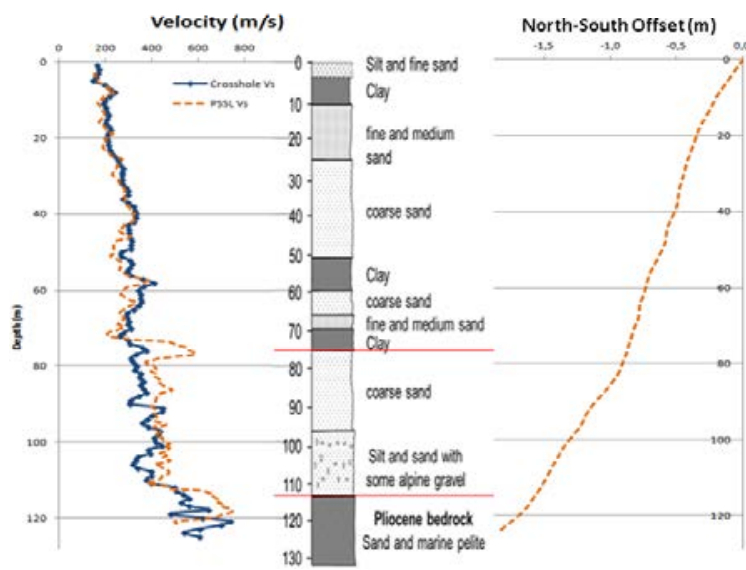

b

Figure 1.28 PSSL tool and downhole DH; a: Caliper variation depending on ground drilling (O. Serra, 1979); b: Mirandola, comparison of DH S and PSSL results, geology and deviation.

This shows that a PSSL analysis also requires control of the diameter (caliper) and the deviation of the borehole (trajectometry), because when its inclination exceeds $30^{\circ}$ the PSSL measurement appears distorted. Finally, due to the length of a PSSL $(5$ to $7 \mathrm{~m}$ ) and the difficulty to achieve a seal that does not overly invade the formation, especially outside of the water table, in a cased hole, there is a frequently observed gap between the measurement of crosshole or downhole and PSSL in the first 10 meters. Figure 1.29 perfectly illustrates this fact. 


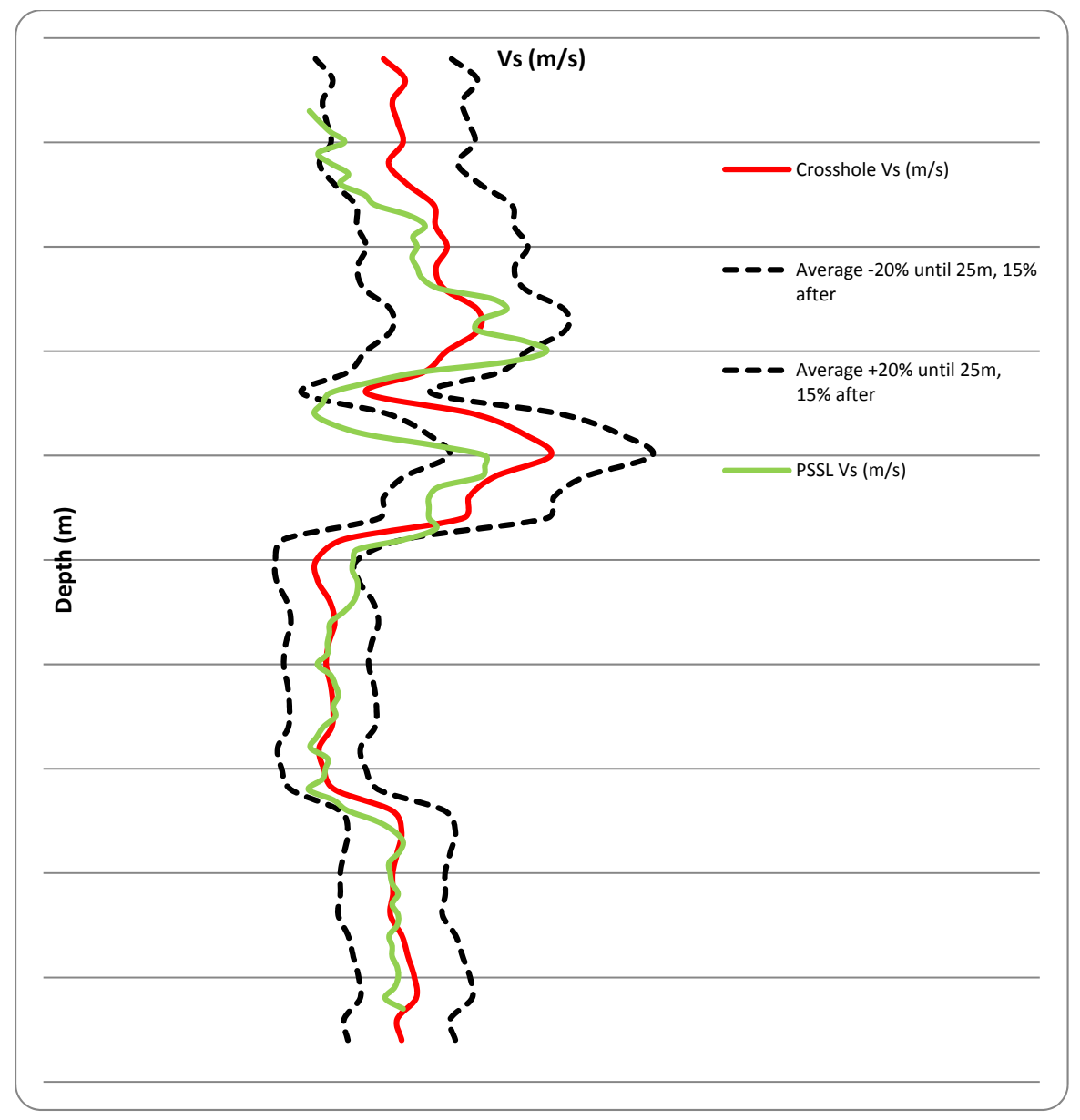

Figure 1.29 Crosshole log vs PSSL in a cased borehole (InterPacific, Grenoble).

Finally, it should be noted that the different probes available on the market clearly have different power levels. Indeed, the 2 acquisitions illustrated in Figure 1.30 were made on the same offshore site, in two open boreholes that were different but did however have key similarities. With the first probe the phase oppositions are clear for the $\mathrm{S}$-waves below $10 \mathrm{~m}$ in depth, while the results of the second probe are unusable. The performance of all PSSL probes is not therefore comparable and a comparative study needs to be carried out. 

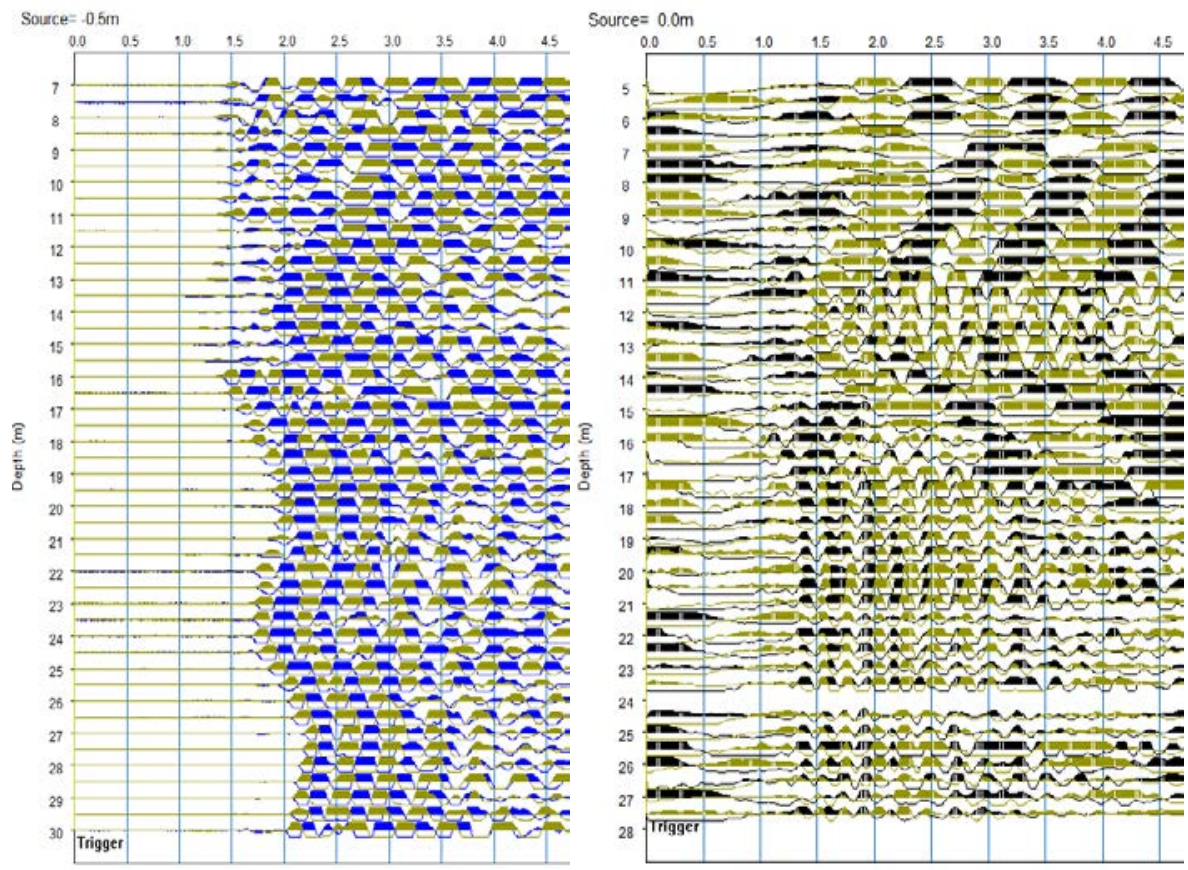

Figure 1.30 PSSL, H component, trace collection for $4.5 \mathrm{~ms}$, in two distinct boreholes but within the same homogeneous site at sea, with $A$ and $B$ probes [EDF-EN].

\subsection{Case study of a downhole acquisition, PSSL and acoustic logging, in the same borehole}

The studied borehole is complex in that it is relatively deep $(280 \mathrm{~m})$, it crosses terrain that is outside of the water table as well as underneath it (the water table is at 3 or $5 \mathrm{~m}$ ), there are unstable formations that require borehole casing (alluvial), and stable ground where the borehole is supported by a bentonite based mud, and finally bedrock at $225 \mathrm{~m}$ deep. This high variability in geological and drilling conditions made it necessary to anticipate the implementation of various techniques for measuring the seismic wave velocity in the borehole. Ultimately, the validated results perfectly illustrate the most suited terrain for each method. Namely:

- Downhole logging is suitable for a borehole that goes through unstable formations and is fitted with PVC casing, 
- PSSL logging is suitable for a borehole going through a "slow" formation, the hole of which is uncased, and which is supported by bentonite-based fluid,

- Acoustic logging is suitable for "fast" formations, i.e. bedrock.

The continuity between cased and uncased hole measurements was ensured by a downhole section in an open hole (see orange dotted line on the "downhole log" in Figure 1.31); it would also have been possible to carry out a PSSL in a cased hole.

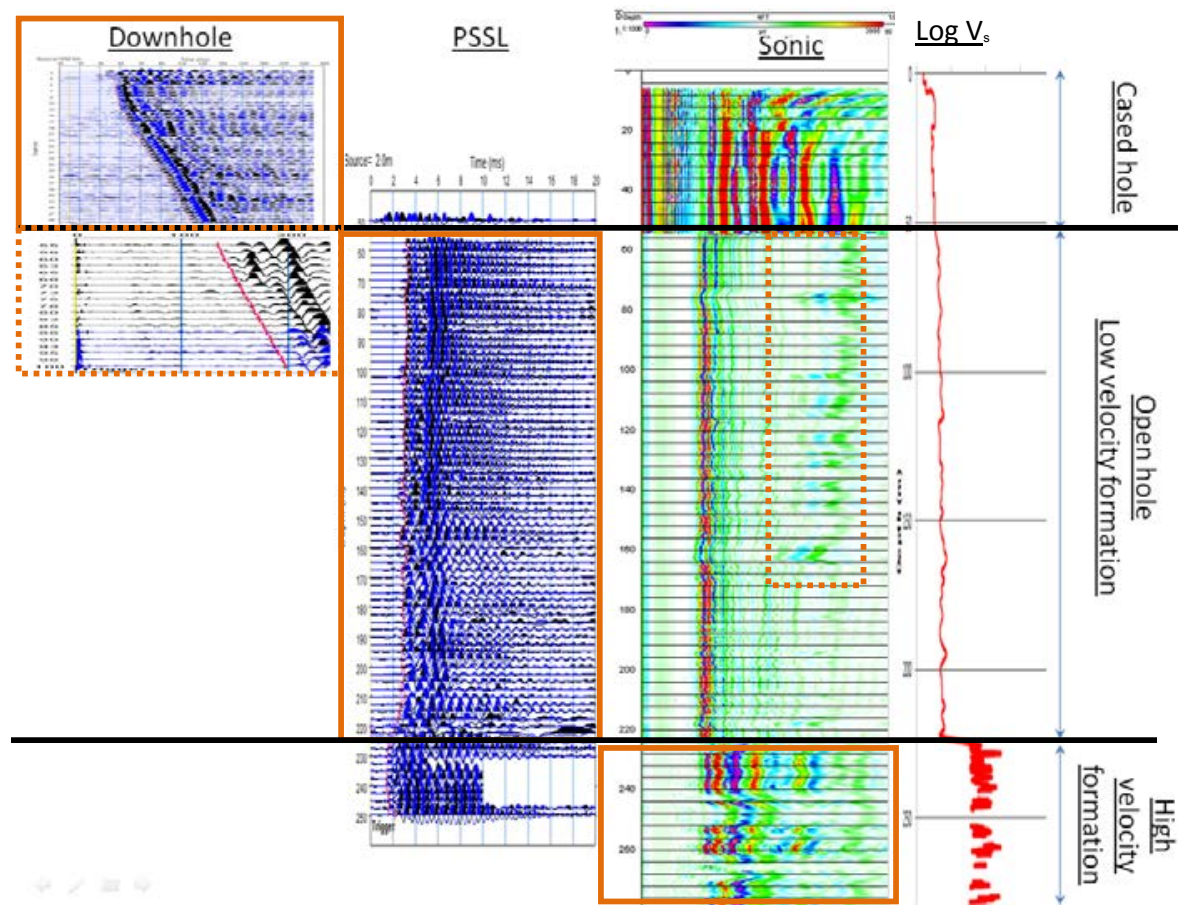

Figure $1.31 V_{s} \log ($ red) obtained from a downhole, PSSL and a "FWF sonic".

The continuity between the measurements in the slow and fast formations was ensured by the recording of Stoneley waves, which are very clear between 55 and $160 \mathrm{~m}$ (see orange dotted line on the "sonic log" in Figure 1.31).

The final log combines the downhole measurement between 0 and $50 \mathrm{~m}$, the PSSL measurement between 56 and $225 \mathrm{~m}$ and the acoustic measurement between 225 and $280 \mathrm{~m}$ (see orange rectangles in Figure 1.31). 
Table 1.5 Velocity measurement $\left(V_{p}, V_{s}\right)$ and tools ( $D H$, sonic, PSSL).

\begin{tabular}{|c|c|c|c|c|c|c|c|c|}
\hline \multirow[b]{2}{*}{ Depth (m) } & \multirow[t]{2}{*}{ Features } & \multicolumn{3}{|c|}{$V_{p}$} & \multicolumn{3}{|c|}{ Vs } & \multirow{2}{*}{$\begin{array}{c}\text { V stonley }=>\text { Vs } \\
\text { Sonic }\end{array}$} \\
\hline & & DH & Sonic & PSSL & DH & Sonic & PSSL & \\
\hline $0-50$ & Cased hole & & & & & & & \\
\hline $55-100$ & Slow formation, & & & & & & & \\
\hline $100-225$ & open hole & & & & & & & \\
\hline $225-280$ & Bedrock, open hole & & & & & & & \\
\hline
\end{tabular}

Table 1.5 summarizes the validated measurements, with dark green shading to show those selected to carry out $\mathrm{V}_{s}$ logging, and light green shading to show those that make it possible to verify the continuity between the different techniques applied. Figure 1.31 is a composite that illustrates all of these conclusions for $S$ measurement.

\subsection{Conclusion}

This chapter has detailed the methodology for the acquisition and analysis of invasive measurements in downhole, uphole and crosshole-type boreholes and loggings. It brings a new perspective compared to the ASTM standards, particularly regarding:

- the possibility of controlling cementation,

- the need to establish calibration procedures for geophysical measurements, and trajectometry and inclinometry tools,

- the impact of downhole tube waves,

- the possibility of working with 2 crosshole boreholes, providing that certain precautions are taken,

- the need to dissociate the P and S acquisition, whether in downhole or crosshole,

- the need for a 2-phase analysis to avoid artefacts related to real paths or refracted waves.

For deep reconnaissance where an uncased hole can be used, PSSL is undoubtedly the best option. The measurement can be complemented by Stoneley wave FWF sonic logging to improve the vertical resolution. However, it is preferable to have a surplus of data for the first meters, with a downhole or crosshole, because this section is usually cased, outside of the water table, and an invasion of the formation by the sealant, which would distort PSSL measurement, cannot be excluded. For the higher part of the borehole, it is also recommended to carry out a "caliper" as well as a deviation measurement (trajectometry). Finally, the choice of PSSL probe is important because PSSL probe performance does not seem to be uniform. A detailed study of the performances of these probes remains to be carried out. 


\section{References}

ASTM D4428/D4428M-14, 2014, Standard test methods for Cross-Hole seismic testing. West Conshohocken (PA): ASTM International, www.astm.org.

ASTM D7400-14, 2014, Standard test methods for Down-Hole seismic testing. West Conshohocken (PA): ASTM International, www.astm.org.

Bourbié Th., Coussy O., Zinszner B., 1986, Acoustique des milieux poreux. Éditions Technip, Paris.

Eurocode 8, Calcul des structures pour leur résistance aux séismes, 2005.

Garofalo F., Foti S., Hollender F., Bard P.Y., Cornou C., Cox B.R., Dechamp A., Ohrnberger M., Perron V., Sicilia D., Teague D., Vergniault C., 2016, InterPacific project: Comparison of invasive and non-invasive methods for seismic site characterization. Part II: Inter-comparison between surface-wave and borehole methods, Soil Dynamics and earthquake Engineering.

SeisImager downhole manual, 2013, Windows Software for Analysis of Downhole Seismic, Pickwin v. 5.1.0.5, PSLog v. 2.0.0.3, Manual v. 1.2. 
